\title{
THE TRANSITIONAL COSTS OF SECTORAL REALLOCATION: EVIDENCE FROM THE CLEAN AIR ACT AND THE WORKFORCE
}

\author{
by
}

\author{
W. Reed Walker * \\ Columbia University
}

CES 12-02

January, 2012

The research program of the Center for Economic Studies (CES) produces a wide range of economic analyses to improve the statistical programs of the U.S. Census Bureau. Many of these analyses take the form of CES research papers. The papers have not undergone the review accorded Census Bureau publications and no endorsement should be inferred. Any opinions and conclusions expressed herein are those of the author(s) and do not necessarily represent the views of the U.S. Census Bureau. All results have been reviewed to ensure that no confidential information is disclosed. Republication in whole or part must be cleared with the authors.

To obtain information about the series, see www.census.gov/ces or contact Cheryl Grim, Editor, Discussion Papers, U.S. Census Bureau, Center for Economic Studies, 4600 Silver Hill Road, Washington, DC 20233, CES.Papers.List@census.gov. 


\begin{abstract}
New environmental regulations lead to a rearrangement of production away from polluting industries, and workers in those industries are adversely affected. This paper uses linked worker-firm data in the United States to estimate the transitional costs associated with reallocating workers from newly regulated industries to other sectors of the economy. The focus on workers rather than industries as the unit of analysis allows me to examine previously unobserved economic outcomes such as non-employment and long run earnings losses from job transitions, both of which are critical to understanding the reallocative costs associated with these policies. Using panel variation induced by the 1990 Clean Air Act Amendments (CAAA), I find that the reallocative costs of environmental policy are significant. Workers in newly regulated plants experienced, in aggregate, more than $\$ 9$ billion inforegone earnings for the years after the change in policy. Most of these costs are driven by non-employment and lower earnings in future employment, while earnings of workers who remain with their firm change little. Relative to the estimated benefits of the 1990 CAAA, these one-time transitional costs are small. However, the estimated costs far exceed the workforce compensation policies designed to mitigate some of these earnings losses.
\end{abstract}

*I would like to thank Janet Currie, Bernard Salanié, Wolfram Schlenker, and Till von Wachter for invaluable advice and discussions. I would also like to thank Alex Chinco, Lucas Davis, Olivier Deschenes, Walker Hanlon, Solomon Hsiang, Wojciech Kopczuk, Matt Kotchen, Todd Kumler, Erin Mansur, Ben Marx, Matt Nodowidigdo, Johannes Schmieder, Eric Verhoogen, Jonathan Vogel, and seminar participants at the Census Bureau, the NBER Environmental and Energy Economics meetings, Arizona State, Columbia, Cornell, and Yale University for useful comments. Any opinions and conclusions expressed herein are those of the author and do not necessarily represent the views of the U.S. Census Bureau. All results have been reviewed to ensure that no confidential information is disclosed. This research uses data from the Census Bureau's Longitudinal Employer Household Dynamics Program, which was partially supported by the following NSF Grants SES-9978093, SES-0339191 and ITR-0427889; NIA Grant AG018854; and grants from the Alfred P. Sloan Foundation. Support for this research from the EPA Grant 834259010 is gratefully acknowledged. 


\section{Introduction}

Environmental policy pertaining to air pollution has been estimated to have large health benefits (Environmental Protection Agency 1999, Chay and Greenstone 2003b, Currie and Neidell 2005). However, these policies also come with costs. Production is typically reallocated away from newly regulated industries to other sectors and locations (Henderson 1996, Greenstone 2002), and this creates a broad set of private and social costs. In terms of labor inputs, this reallocation is often framed in terms of "jobs lost", and the distinction between "jobs versus the environment" is one of the more politically salient aspects of these regulations. ${ }^{1}$ However, workers often find new jobs elsewhere, perhaps in different locations and/or industries. If workers simply transition from one employer to the next without significant earnings loss, then job loss should not be considered a cost when evaluating policy. If workers lose job or industry specific skills and/or experience long periods of unemployment following job transitions, the cost of reallocating the workforce could be quite large. There also may be costs to workers who remain in these potentially less productive industries.

This paper uses newly available longitudinal data on workers and firms to estimate the economic costs of regulation-induced worker reallocation stemming from the 1990 Clean Air Act Amendments. In doing so, this paper offers an approach to characterizing the costs and consequences of external labor market innovations when production and workers are not instantly reallocated elsewhere within the economy. Using the confidential Longitudinal Employer Household Dynamics (LEHD) dataset from the United States Census Bureau, I am able to follow workers across their jobs over time to explicitly incorporate two substantive features of labor market adjustment: the wage costs borne by workers who remain in the newly-regulated, now less productive, sector and the long-run earnings losses for those who leave the sector.

The 1990 CAA Amendments created a new class of pollution standards and strengthened existing standards so that many areas of the United States fell under a new regulatory regime. Polluting firms in these areas were forced to reduce emissions and install new pollution abatement technologies, increasing the cost of production and lowering productivity (Greenstone, List, and Syverson 2010). These regulations led to a sectoral shift in production and employment away from newly regulated, polluting sectors (Walker 2011). The empirical framework estimates the impact of this regulatory shock on the evolution of earnings for the workers in newly regulated plants.

While the empirical setting pertains to environmental regulations, the analysis relates to a large literature on the costs and incidence of labor market adjustment to external factors such as trade, immigration, or innovations in labor demand. ${ }^{2}$ Traditionally, work in this area examines how prices in industries or regional labor markets

\footnotetext{
${ }^{1}$ For representative examples from the popular press see the Wall Street Journal (July 26, 2011) op-ed entitled "The Latest Job Killer from the EPA", "Smoke Signals" from The New Republic (April 7th, 2011), or "A Debate Arises on Job Creation and Environment" from The New York Times (Sep 4th, 2011).

${ }^{2}$ The empirical literature on labor market adjustment to external factors is vast. For related work studying the impact of international trade on labor markets see: Borjas and Ramey (1995), Menezes-Filho and Muendler (2007), Artuc, Chaudhuri, and McLaren (2010),
} 
respond to external labor market shocks, and then the estimates are used to back out a measure of welfare or incidence. This approach is sufficient if labor markets are competitive, workers are perfectly mobile, and labor markets are in continuous equilibrium. However, in the short and medium-run, this is unlikely to be the case. Disequilibrium in the labor market and/or non-competitive wage setting implies that external shocks may also contribute to changes in non-wage outcomes such as increases in sector-specific unemployment through short-run job rationing. These labor market outcomes, while important, are unobserved with existing local labor market data. The novelty of this paper is that the baseline earnings estimates explicitly incorporate both worker-specific non-employment durations and any long run earnings changes associated with the reallocation of production and workers. In doing so, this is the first paper to jointly estimate the long run earnings changes for workers who remain in a sector and the long run earnings changes for workers who leave the sector when measuring the total wage costs of labor reallocation in the context of external labor market shocks.

This paper departs from the existing literature in four important ways. First, prior research on the labor market impacts of environmental regulation has primarily focused on employment in manufacturing industries (Berman and Bui 2001, Greenstone 2002, Deschenes 2010, Kahn and Mansur 2010, Walker 2011). ${ }^{3}$ For example, Greenstone (2002) finds that the Clean Air Act Amendments of the 1970's led to a loss of more than 500,000 jobs in regulated sectors relative to unregulated sectors. However, it is difficult to monetize the effects of job loss without knowing the long-run earnings losses associated with these job transitions. Numerous papers have highlighted the lack of credible estimates pertaining to the costs and economic incidence of environmental regulations for workers in these industries (see e.g. Jaffe, Peterson, Portney, and Stavins (1995), Arrow, Cropper, Eads, Hahn, Lave, Noll, Portney, Russell, Schmalensee, Smith, and Stavins (1996), Greenstone (2002), Environmental Protection Agency (2005), Fullerton (2008), Congressional Budget Office (2009)). In contrast to the existing work on environmental regulation and labor demand, the estimates from this analysis, which consist of the total foregone wage bill denominated in dollars, can be directly plugged into a cost-benefit analysis of the Clean Air Act.

Second, it is widely acknowledged that industry level wage and employment data are likely to be misleading in terms of labor market incidence, especially when labor markets are not fully competitive and/or are not in continuous equilibrium. A large literature has documented barriers to the short-run adjustment of wages to

Ebenstein, Harrison, McMillan, and Phillips (2011), Feenstra (2010), Topalova (2010), Autor, Dorn, and Hanson (2011), and DixCarneiro (2011); related work on immigration and labor markets includes: Friedberg and Hunt (1995), Borjas, Freeman, and Katz (1997), Card (2001), Borjas (2003), and Ottaviano and Peri (2006); lastly, work looking more generally at labor market adjustment to innovations in labor demand includes: Topel (1986), Bartik (1991), Blanchard and Katz (1992), Bound and Holzer (2000), Moretti (2011), Notowidigdo (2011).

${ }^{3}$ There is a large literature examining industry responsiveness to regulatory changes stemming from the Clean Air Act. While not explicitly interested in labor demand, other research has found that plants on the margin of production may opt to close or relocate in response to these regulations (Henderson 1996, Becker and Henderson 2000). Other work suggests that regulations may increase barriers to entry, reducing plant entry rates, increasing market concentration, and reducing output (List, Millimet, Fredriksson, and McHone 2003, Ryan 2011). 
productivity or labor market conditions. ${ }^{4}$ These barriers may constrain wages to remain above market-clearing levels, leading to a shortage of jobs. In such a case, industry wages may respond minimally to external shocks, while a large fraction of workers in these industries may now be without jobs. Moreover, industry wages do not reflect the long run costs of job loss for affected workers, since workers are often unemployed between jobs and/or transition to other sectors of the economy (see e.g. Jacobson, LaLonde, and Sullivan (1993), von Wachter, Song, and Manchester (2009)). ${ }^{5}$ Lastly, if firms and industries respond to shocks by laying off their least able or least senior workers (Abraham and Medoff 1984, Gibbons and Katz 1991), then industry wages will be biased by these compositional changes in the workforce (e.g. more productive workers remain ex-post) (Solon, Barsky, and Parker 1994).

In contrast to existing work, I exploit detailed longitudinal data to follow workers over time and across jobs. The use of longitudinal data on workers overcomes many of the existing limitations outlined above. The primary estimation framework follows cohorts of workers in newly regulated counties and sectors over time, before and after plant-specific regulatory changes. The cohort-style analysis is meant to address concerns pertaining to compositional biases (i.e. the composition of workers is constant by construction) while also incorporating potentially costly job transitions into the average earnings estimates. By following cohorts, the baseline earnings estimates consist of both the long run earnings changes for workers who remain in the newly regulated sector as well as the long run earnings changes of the workers who leave the sector. Both of these earnings components are crucial for understanding the wage costs of labor reallocation, but due to data limitations they are most often studied in isolation.

The third departure from previous work comes from the use of a new, plant-level dataset from the Environmental Protection Agency (EPA) that details exactly which plants are regulated under the various environmental programs in the United States. The Clean Air Act regulations apply heterogeneously within certain industries. Prior literature in this area has had to rely on more aggregate, industry-level proxies for environmental regulation since this plant-level data was not yet available. ${ }^{6}$ I match this database to administrative, plant-level data from the U.S. Census Bureau, allowing me to observe plant-level regulatory status over time.

Fourth, this paper is also able to lend insight as to how workers and labor markets adjust to sector specific shocks. Existing evidence suggests that local labor markets adjust to innovations in labor demand primarily through worker migration across labor markets (Blanchard and Katz 1992, Bound and Holzer 2000). However, this evidence is somewhat indirect as existing data does not permit fine-grained analysis of worker transitions. ${ }^{7}$

\footnotetext{
${ }^{4}$ The literature on wage rigidity is vast. Examples include Baker, Gibbs, and Holmstrom (1994), Campbell III and Kamlani (1997), Altonji and Devereux (1999), Bewley (1999), Fehr and Goette (2005).

${ }^{5}$ Involuntary job separations accounted for almost $45 \%$ of all job separations in the manufacturing industry from 2001 to 2008 according to the Bureau of Labor Statistics Job Openings and Labor Turnover Survey (JOLTS).

${ }^{6}$ Berman and Bui (2001) is an exception. However, they only focus on the Southern California Air Basin and oil refineries.

${ }^{7}$ Previous research examining labor market responses to innovations in labor demand either relies on aggregate state-level data (see e.g. Topel (1986) and Blanchard and Katz (1992)) or long panels incapable of identifying detailed dynamic responses to shocks (see
} 
This project combines both geographic and temporal detail to observe and estimate transitional dynamics surrounding wage and mobility responses to regulatory shocks.

The results in this paper suggest that the reallocative costs to the workforce from the 1990 Clean Air Act Amendments are significant, but remain far below most estimated benefits of the policy. For those workers in the regulated sector prior to the change in regulation, the average earnings declined by more than 5 percent in the 3 years after the regulation. These earnings declines are persistent and only begin to recover some 5 years after the policy. The average worker in a regulated sector experienced a total earnings loss equivalent to 23 percent of their pre-regulatory earnings. In aggregate, the total foregone wage bill associated with this regulation-induced sectoral shift in production is estimated to be more than 9 billion dollars (in 1990 dollars). These foregone earnings estimates are two orders of magnitude below most estimates of the health benefits of the 1990 Clean Air Act Amendments.

I explore the mechanisms generating these earnings changes by stratifying the sample into those employees who stay with their firm versus those who leave to a new job in another location or sector. While a job separation is endogenous in this setting, comparisons across the two groups provide striking contrasts in the earnings adjustment process for these sets of workers. Workers who remain at a firm in the newly affected sector experience no discernible earnings change, whereas those who separate see both sizable and persistent earnings losses. Consistent with these results, estimates using average industry earnings measures show little responsiveness to these regulations, highlighting the importance of longitudinal data when characterizing the costs and incidence of labor market adjustment.

The rest of the paper is organized as follows: The following section discusses the details of the Clean Air Act more fully with a brief discussion of the previous literature. Section 3 presents a simple conceptual framework to motivate the empirical analysis as well as highlight key differences between this project and existing work in this area. Sections 4 and 5 discuss the research design and data while Sections 6 and 7 present an econometric framework and estimation results. Section 8 offers a short discussion of the results. Section 9 concludes.

\section{The Clean Air Act and Environmental Regulation}

Air pollution regulation in the United States is coordinated under the Clean Air Act, the largest environmental program in the United States. The Clean Air Act requires the EPA to develop and enforce regulations to protect the general public from exposure to airborne contaminants that are known to be hazardous to human health. The Act was passed in 1963 and significantly amended in 1970, 1977, and 1990. The enactment of the Clean Air Act of 1970 resulted in a major shift in the federal government's role in air pollution control, authorizing federal and state regulations to limit emissions. In doing so, the EPA established national ambient air quality

e.g. Bound and Holzer (2000) and Notowidigdo (2011)). 
standards (NAAQS) which specify the minimum level of air quality acceptable for six criteria air pollutants. ${ }^{8}$

The 1977 Clean Air Act Amendments stipulated that every county in the U.S. must be designated annually as being in-attainment or out-of-attainment (nonattainment) of NAAQS. When a county is out of attainment for one of the regulated pollutants, the EPA requires states to adopt regulatory plans, known as State Implementation Plans (SIPs), to bring their county into compliance. The EPA can impose sanctions in areas that fail to comply with these requirements, where sanctions include the withholding of federal grant monies (e.g., highway construction funds), direct EPA enforcement and control (through Federal Implementation Plans), and bans on the construction of new establishments with the potential to pollute. ${ }^{9}$

The regulatory plans require polluting plants locating in a county labeled as out-of-attainment, or substantially expanding operations at an existing plant, to adopt "lowest achievable emission rates" (LAER) technologies without regard to costs. Moreover, any new emissions from plant entry or investment/expansion must be offset from an existing source within the same county. In contrast, in areas designated as "attainment", large polluting plants must use "best available control technology" (BACT). In cases concerning BACT, the economic burden on the plant is considered in arriving at a final solution. Using plant-level survey evidence, Becker (2005) finds that BACT is significantly less costly to plants than LAER technology. Since SIPs require states to develop plant-specific regulations for every major source of air pollution, existing plants in nonattainment areas also face greater regulatory scrutiny than plants in attainment areas. These plant-specific regulations typically have come in the form of emissions limits. Regulatory compliance may also necessitate redesigns in production processes, introducing additional costs if output must be suspended in the interim (Becker and Henderson 2000). Becker and Henderson (2001) attempt to quantify these costs using plant-level data from the Census of Manufactures. They estimate that total operating costs were $17 \%$ higher in polluting plants from nonattainment areas relative to similar plants in attainment areas. In addition to the increased abatement expenditures, inspections and oversight are more persistent in nonattainment areas.

The Clean Air Act Amendments of 1990 introduced a new NAAQS standard (PM-10) and formally required all polluters to obtain an operating permit for operation. ${ }^{10}$ The requirement that polluting sources obtain operating permits is crucial for this study, as it allows one to observe regulatory status at the plant level, something that has not been possible in previous work in this literature. The EPA also formally evaluated their existing nonattainment designations for each air region so that 133 counties found themselves in nonattainment

\footnotetext{
${ }^{8}$ These pollutants consist of sulfur dioxide $\left(\mathrm{SO}_{2}\right)$, particulates (TSP, PM2.5, and PM10), nitrogen dioxide $\left(\mathrm{NO}_{2}\right)$, carbon monoxide (CO), ozone, and lead.

${ }^{9}$ A 1999 report by the Congressional Research Service (McCarthy 1999) states that 858 notices of impending sanctions were issued by EPA between 1990 and October 1999. Becker (2005) notes that the vast majority of these CAA violations were rectified within the 18-month grace period following formal notification. Sanctions were imposed in 18 instances and a second round of additional sanctions was administered in two of those cases.

${ }^{10}$ Title IV of the 1990 Clean Air Act Amendment established a tradeable market for sulfur dioxide emissions. These markets apply nationally, are primarily for electric utilities, and do not correspond to the variation in nonattainment designation used in this study.
} 
for at least one new pollutant, a 33\% increase. Appendix Figure B.1 shows the 1990 CAA Amendments led to by far the largest documented increase in county nonattainment designations since 1978.

In no small part due to these regulations, pollution levels have declined considerably from 1970 levels (Henderson 1996, Chay and Greenstone 2003a). More recently, since 1990 pollution levels have declined even further despite GDP rising, vehicle miles traveled increasing, population growing, and energy consumption rising by more than 20 percent (Environmental Protection Agency 2008, Auffhammer, Bento, and Lowe 2009). The combined evidence suggests that nonattainment designations are effective at reducing pollution levels, and much of this reduction comes through increased firm compliance. The following section presents a simple conceptual framework designed to map these regulatory changes into worker outcomes and motivate the empirical analysis.

\section{A Mapping Between Regulatory Change and Reallocative Incidence}

New regulations force plants to install pollution abatement technologies, so that for a given level of output plants must now use more inputs. Therefore, a straightforward way to model environmental regulations is to view these regulations as affecting plant level productivity. ${ }^{11}$ This is consistent with recent empirical evidence suggesting that CAA nonattainment designation lowers plant-level total factor productivity (Greenstone, List, and Syverson 2010). This modeling decision foregoes potential complementarities between pollution abatement and capital or labor while allowing for a more general treatment of labor reallocation in the context of productivity shocks. I will treat the industry as competitive, with price being set on an international market. Thus, a reduction in sectoral productivity will lead to a reduction in sectoral output as well as a reduction in the demand for inputs. ${ }^{12}$

In order to map these changes in factor demands into worker outcomes, consider the following partialequilibrium Roy (1951) model of occupational choice. ${ }^{13}$ A population of $N$ workers supply an indivisible unit of labor to a sector $s \in\{p, o\}$ (i.e. the polluting sector $p$ or the outside sector $o$ ). Both sectors are assumed large so that any movements across sectors do not affect wages through movements in the labor supply curve. Each worker is endowed with sector-specific ability $w_{i s} \geq 0$, and workers are paid according to their ability in each

\footnotetext{
${ }^{11}$ There are many ways to model pollution or pollution abatement within a plant level production decision (see e.g. Copeland and Taylor (2004)). In particular, note that if environmental regulations are factor biased (e.g. by increasing the rental rate of capital), the total effect of regulation on labor demand is ambiguous depending on both the elasticity of substitution between capital and labor and any "scale effect" associated with changes in industry output.

${ }^{12}$ In a dynamic setting, there may also be interactions between plants' endogenous production decisions in the context of these regulations (e.g. Jovanovic (1982) and Hopenhayn (1992)). Moreover, shifts in the costs of entry and investment can lead to markets with fewer firms and lower production (Ryan 2011).

${ }^{13}$ The partial equilibrium assumption is not necessary for generating the main implications from this exercise. It is primarily chosen for simplicity. The same conclusions may be reached in the context of a general equilibrium Roy model (e.g. Heckman and Sedlacek (1985)) by adding a competitive production sector, at the cost of additional notation.
} 
sector. Agents are free to enter the sector that gives them the highest income. However, they can work in only one sector at a time.

Workers are income maximizing and do not value leisure so that utility for a worker $i$ may be written as

$$
U_{i}=\max \left\{w_{i o}, w_{i p}\right\}
$$

Worker $i$ simply chooses a sector $s$ that maximizes utility with full knowledge of their ability component in each sector. Workers self-select into the sector for which they have comparative advantage. Define the indicator variable $D_{i s}=1$ when sector $s$ satisfies individual $i$ 's maximization criterion. The total utility of the workers in sector $s$ may be written as

$$
W_{s}=\sum_{i=1}^{N}\left(D_{i s} \times w_{i s}\right)
$$

which is simply equal to the total wage bill for workers in sector $s$.

\subsection{The Incidence of Regulation for Polluting Sector Workers}

As a result of this regulatory shock, both output and demand for inputs fall. ${ }^{14}$ In a competitive labor market, holding labor supply fixed, a reduction in labor demand will reduce the wage from $w_{i p}$ to $w_{i p}^{\prime}$. As skill prices vary, individuals shift sectors in pursuit of their comparative advantage. ${ }^{15}$

In the new regulatory regime, some workers who originally chose the polluting sector $p$ will now choose the outside sector $o$. The structure of the model also tells us which workers switch, namely those who now have comparative advantage in the outside sector. On average, these are low-wage workers in the polluting sector, which implies the average wage of workers in the polluting sector may be higher after the regulations go into place. In such a case, the average wage in the polluting sector $p$ may rise, not because of a shift in the labor supply curve, but instead because the remaining workers are, on average, more productive than before. This reflects the well-known empirical issue pertaining to composition bias in aggregate wage regressions - the workers who stay in a sector and the workers who leave the sector are selected (see e.g. Solon, Barsky, and Parker (1994)).

Now consider the effect of the change in regulations on the workers in the polluting sector $p$. Denote the set of workers in the polluting sector prior to the policy change as $N_{p}$ :

$$
N_{p}=\left\{w_{i p}: w_{i p}>w_{i o}\right\}
$$

\footnotetext{
${ }^{14}$ Here, the implicit assumption is that regulations are factor neutral with respect to production.

${ }^{15}$ There is no involuntary job loss in this model. This is taken as a modeling convenience, but the implications remain similar to models with heterogeneous workers that endogenize the demand-side job separations; least productive workers are laid off in response to negative demand shocks. See e.g. Gibbons and Katz (1991).
} 
Write the wage bill for the subset of these workers better off in sector $o$ after the regulations as $\left.W_{o}\right|_{i \in N_{p}}$ and the wage bill of those who remain in sector $p$ after the regulations as $\left.W_{p}^{\prime}\right|_{i \in N_{p}}$. The change in utility for workers in the polluting sector prior to the regulations may be written as:

$$
\begin{aligned}
\left.\Delta W\right|_{i \in N_{p}} & =\left(\left.W_{p}^{\prime}\right|_{i \in N_{p}}+\left.W_{o}\right|_{i \in N_{p}}\right)-W_{p} \\
& =\sum_{i \in N_{p}}(\underbrace{D_{i p}^{\prime} \times\left(w_{i p}^{\prime}-w_{i p}\right)}_{\text {Wage Change for Stayers }}+\underbrace{D_{i o}^{\prime} \times\left(w_{i o}-w_{i p}\right)}_{\text {Wage Change for Leavers }}),
\end{aligned}
$$

where $D_{i s}^{\prime}$ is the re-optimized decision rule pertaining to sector $s$ under the new regulatory regime. Equation (1) suggests that we can write the change in utility for workers in the polluting sector as a sum of two components: the first component represents the wage costs for the inframarginal workers (i.e. those workers not induced to switch sectors by the productivity shock), and the second component represents the wage costs for those workers who are now better off in sector $o$. The latter term consists of the difference between the individual's wage in the outside sector $w_{i o}$ and the wage the worker received in the previous sector $w_{i p}$. Note that in this partial equilibrium framework, both terms are negative. The sign of the first term inside the brackets is negative due to a reduction in the productivity of all workers in the sector; the sign of the second term is negative, since any worker now in the outside sector $o$ had optimally chosen sector $p$ to begin with.

This framework highlights two important components pertaining to reallocative incidence in the context of any external labor market shock. First, the total change in utility for workers in the polluting sector consists of both the wage changes for those who remain in the sector and any change in wages experienced by those who leave the sector. Second, the framework highlights the econometric challenges faced in estimating either of these components in isolation - namely both workers who stay and workers who leave are selected.

With this in mind, I develop an econometric framework to match the main features of equation (1). The empirical analysis focuses on all workers who had chosen to work in the polluting sector prior to the change in regulations and then estimates the change in earnings for this subset of workers after the policy change. Since the theoretical framework suggests that workers who remain in the sector are positively selected and those who leave are negatively selected, the baseline regression estimates refrain from separating these two components, instead focusing on the average wage change for stayers and leavers. Since I am following the same group of workers before and after the policy change, concerns pertaining to composition bias no longer apply (i.e. the composition is explicitly held constant). 


\subsection{Regulatory Effects in General Equilibrium}

While regulations affect workers in the polluting sector, employment flows away from the regulated sector may affect factor prices in other, non-regulated sectors or locations. This section highlights these relevant factor price adjustments in the context of a stylized general equilibrium model.

Consider a closed economy with two locations (attainment and nonattainment) and two sectors in each location (polluting and non-polluting) that produce freely tradable goods using a single input (labor). Labor is heterogeneous in the sense implied by the previous section: workers differ in their sector specific productivity. Workers consume production goods. Assuming perfectly competitive markets, all prices (wages and prices for polluting and non-polluting goods) are set such that each market clears.

Regulations lower productivity in the polluting sector of nonattainment counties, which will lower polluting sector wages in those counties. Marginal workers leave the polluting sector, finding work either in the nonpolluting sector of the nonattainment location or in either sector of the attainment location. This will increase the sectoral labor supply in all sectors, which will drive down the wage in those sectors (depending on the total increase in labor supply and the labor demand elasticity of each sector). ${ }^{16,17}$ These effects suggest that relative geographic comparisons will overstate changes in labor demand (i.e. double counting) and understate wage declines in the regulated location. These will be important considerations for interpreting the empirical estimates to follow, and I will present a series of tests speaking to the relative importance of these spillovers in the context of the research design.

\section{The Clean Air Act as a Research Design}

The previous section highlighted the empirical challenges faced when estimating earnings regressions separately for groups of workers who remain in a sector and groups of workers who leave the sector, while also providing a straightforward solution - estimate the earnings components jointly, not conditioning on job separation. One remaining empirical challenge is that plant-level regulations are not randomly assigned. In addition, workers are not randomly assigned to firms. Instead, firm and worker decisions are made to maximize their respective objective functions. Wages vary tremendously across both firms and locations due to reasons observed and unobserved to the econometrician. Moreover, this variation in the wage structure is likely correlated with a firm's status as a polluter. For example, polluting firms tend to be both older and larger (Becker and Henderson 2000, Walker 2011), and larger plants tend to pay significant wage premia (Brown and Medoff 1989). Workers

\footnotetext{
${ }^{16}$ Since labor is relatively less expensive in the newly regulated sector, this could encourage new polluting firms to enter nonattainment counties. However, EPA regulations explicitly prevent new polluting firms from entering, so that all wage adjustment occurs through worker out-migration (rather than new firms entering).

${ }^{17}$ There may also be important general equilibrium spillovers pertaining to compositional changes in the local labor market, workers' bargaining power, and sectoral wage determination. See Beaudry, Green, and Sand (2011) for recent evidence along these lines.
} 
may also demand some form of compensating wage differential associated with potentially harmful working conditions. Therefore, a naive comparison of earnings in polluting and non-polluting firms of nonattainment counties is likely to yield biased estimates. Credible estimates of the effects of new environmental regulations requires the identification of a group of firms and workers that are similar to those affected by the regulations in ways observable and unobservable to the econometrician. The regulatory variation inherent in the design of the CAA provides a solution to this identification problem.

Due to the way in which the CAA is implemented, regulations vary over both time and space. Figure 1a shows counties in the United States that were in nonattainment for any pollutant in 1991. Since only some counties are regulated in a given year, it is possible to estimate models that include flexible controls for nationwide or industry-specific shocks to employment and/or earnings such as the recession in the early 1990's or the phase-in of the North American Free Trade Act throughout the 1990's. Temporal variation in regulations exists from counties that go in and out of nonattainment based on annual pollution levels, allowing for pre-post comparisons within counties, industries, plants, or workers. This means that any time-invariant unobservables unique to these groups may be controlled for by including a set of group-specific fixed effects while still controlling for nationwide trends as detailed above. The inclusion of group-specific fixed effects ensures that estimates are derived only from those sources that experience a change in the regulation - comparing outcomes before and after the change.

A potential issue with time series variation in light of nonattainment designation is that pollution is correlated with economic activity (Chay and Greenstone 2003b). Therefore, counties that switch into nonattainment in a given year may also be more economically vibrant. ${ }^{18}$ To address this issue, this study relies on the discrete policy change induced by the $1990 \mathrm{CAA}$ Amendments. Since the EPA introduced a new pollutant class for PM-10, a group of counties suddenly found themselves in nonattainment relative to the year prior. Figure $1 \mathrm{~b}$ plots only those counties that switched into nonattainment status in 1991, the first year that the 1990 CAAA were adopted. The figure shows that a considerable number of counties were newly regulated with the passage of the 1990 CAAA. Appendix Figure B.1 shows that the 1990 CAAA led to the largest increase in newly regulated counties since 1978 .

Lastly, within any nonattainment county, only polluting plants are regulated and only if they emit the specific pollutant for which the county is in violation. Even within 2-digit industry SIC codes, there is a considerable amount of variation in the fraction of plants that are classified as polluters. Figure 2 plots the fraction of establishments in nonattainment counties that are classified as a polluter by the EPA, split by 2-digit manufacturing SIC codes. Since only the polluting firms within a given county-industry are regulated, it is possible to control for unobservable, county-level economic trends.

All of these sources of variation amount to a research design which examines the earnings outcomes of workers

\footnotetext{
${ }^{18}$ Note that the direction of bias here is clear, and that this type of confounding variation would lead me to understate the effects of the regulations.
} 
in polluting plants of newly regulated counties, before and after the introduction of the plant level regulations all while controlling for fixed, unobservable attributes of these workers, national variation in the polluting/nonpolluting sectors, and county level trends. The following section details how observable characteristics of affected and non-affected sectors may differ across these sources of regulatory variation while also informing the choice of econometric model.

\section{Data Overview and Description}

This project relies upon the most detailed and comprehensive data currently available on both local labor markets as well as the program components of the CAA. To understand the wage costs of the regulations for both workers who remain in an industry and workers who leave, we need longitudinal data both on workers and firms, as well as information detailing which set of firms were subject to these regulations. I have obtained access to two new data sources, heretofore not used to study the effects of local labor market shocks that will be briefly described below. Appendix A provides additional details.

The Longitudinal Employer Household Dynamics Files (LEHD) The primary source of data used in this project comes from the Census Bureau's LEHD file which provides administrative, quarterly earnings records for a large percentage of the United States workforce. ${ }^{19}$ I observe the complete employment history and earnings profile for each worker in the LEHD, conditional on the worker remaining within the reporting states over the course of the sample. Since the administrative earnings records are based on firms' reports that are used to calculate tax liabilities they are presumably free of measurement error, compared to existing survey data (Duncan and Hill 1985, Bound and Krueger 1991). The LEHD also provides important demographic information on workers such as age, race, and education as well as time-varying information from the firms at which they work. This provides a detailed snapshot of local labor markets at any given point in time.

The entire LEHD file consists of over 2.8 billion quarterly earnings records. To limit the computational burden of working with the complete file, I make some important sample restrictions. I begin by restricting the analysis to states in the LEHD that have data prior to the 1991 implementation of the CAAA. This limits the analysis considerably, as the only states that contain 1990 quarterly earnings are Illinois, Maryland, Washington, and Wisconsin. Appendix Table B.1 compares aggregate characteristics of this sample to those from a national sample. The counties in this study comprise 20 percent of the total polluting sector employment share of counties newly regulated by the 1990 CAAA. When comparing newly regulated counties that are both in and out of the sample (i.e. columns (5) and (6) of Table B.1) we see that the newly regulated counties from these 4 states are

\footnotetext{
${ }^{19}$ The full LEHD file currently contains earnings records from over 30 states, with some states containing records as far back as 1985. See Abowd, Stephens, Vilhuber, Andersson, McKinney, Roemer, and Woodcock (2008) and McKinney and Vilhuber (2008) for a comprehensive discussion of both the construction and contents of the LEHD files.
} 
slightly wealthier and have a slightly larger manufacturing base than the rest of the newly regulated counties. These will be important distinctions to consider when extrapolating the earnings estimates from this paper to the rest of counties affected by the 1990 CAAA.

I limit the sample to workers who worked in the manufacturing and electric/gas industries (i.e. 2 digit SIC 20-39, 49) in $1990 .^{20}$ This leaves me with a balanced panel of 3 million workers in 1990 that I track over the course of their next 12 years irrespective of whether or not they remain with their employer, transition outside of the manufacturing sector, or move across state lines. Earnings are deflated by the national-level CPI with the base year index as 1990 .

While the LEHD data are incredibly detailed in some regards, they have several important limitations that bear mention. As is true with most linked worker-firm administrative datasets, it is not possible to distinguish between unemployment and non-participation. ${ }^{21}$ Moreover, the data do not allow the researcher to assess whether a missing earnings record is due to unemployment/non-participation or whether the worker moved outside of the states covered in the data. To reduce biases due to this type of selective sample attrition, I require workers to have at least some positive earnings in a particular year to contribute to earnings estimates. I explore the sensitivity of the results to reclassifying missing data in various ways designed to bound the true value. See Appendix A.1 for further details.

Longitudinal Business Database (LBD) Since the LEHD contains earnings records only as far back as 1990, and the CAA Amendments went into place in 1991, I draw upon another administrative dataset from the Census Bureau to assess whether pre-CAAA trends differ significantly across the main sources of identifying variation. The Longitudinal Business Database (LBD) is a plant level database that covers the universe of establishments in the United States from 1975-2005. ${ }^{22}$ Included in the database is annual information on employment, payroll, and firm age. The database also includes information on detailed industry, location, and entry/exit years for the respective establishments. Thus, I can observe trends in employment and earnings per worker before and after these changes for newly affected sectors relative to unaffected sectors. The LBD also allows me to revisit the previous literature pertaining to CAA regulation and sectoral employment (Greenstone 2002, Walker 2011) to see how sector size (as measured by employment) is related to variation in the regulations. I limit the LBD sample to plants in the manufacturing industry (SIC 20-39), the electric/gas industries (SIC 49), and plants residing in states covered by the LEHD sample.

EPA Air Facility Subsystem (AFS) I match both the LEHD and LBD to plant-level, regulatory micro data from the EPA. The EPA's AFS database is a plant level database that provides information detailing

\footnotetext{
${ }^{20}$ These industries constitute over $90 \%$ of the total number of plants regulated by the EPA. While the electric/gas industry is one of the largest polluting sectors in the United States, electric utilities are also undergoing rapid restructuring over the sample period. I include this sector in the baseline sample while noting that results are not sensitive to this choice.

${ }^{21}$ Using administrative data linked to survey data, Frijters and van der Klaauw (2006) find this distinction not very important for men, but more so for women. Accordingly, I estimate robustness specifications using a sample of only prime-age males 25-55.

${ }^{22}$ I only have access to the LBD from 1985-2005.
} 
the regulatory programs for which the plant is permitted (and regulated) as well as the specific pollutants for which the permit is issued. ${ }^{23}$ An important aspect of this project is the ability to observe plant level regulatory status over time. In doing so, this project is the first to use the AFS data to examine the effects of plant level regulatory status on firm and worker outcomes. ${ }^{24}$ Using the Census Bureau's Standard Statistical Establishment List (SSEL), I am able to link the LEHD and LBD to plant-level regulatory and permit data from the EPA's Air Facility Subsystem (AFS) using a name and address matching algorithm. The exact details of the matching algorithm as well as the match rates are described in Appendix A.4.

One limitation of the AFS data is that it does not provide any information as to when these operating permits were issued. Fortunately, the regulatory structure of the CAA allows one to infer the timing of the regulations based on the county nonattainment status. Specifically, I define a plant as regulated if the plant has an operating permit in the AFS database and that plant resides in a county that is in nonattainment for the specific pollutant on the permit. This plant level definition of regulation is in contrast to previous research for which regulation was proxied by 2- and 4-digit SIC-level national pollution estimates (Greenstone 2002, List, Millimet, Fredriksson, and McHone 2003, Becker 2005, Kahn and Mansur 2010, Greenstone, List, and Syverson 2010). Lastly, I match the EPA's annual county level nonattainment designations to each dataset.

\subsection{Aggregation}

The linked worker-firm sample from the LEHD consists of a balanced panel of 3 million workers for 12 years in the data so that the baseline sample consists of 36 million annual earnings observations. For the baseline empirical analysis, I aggregate the data in two separate ways. First, I compute the average earnings and employment in each county $\times$ sector $\times$ year in order to see how aggregate sectoral employment and wages respond to changes in regulatory status. Each county has two observations in a given year, one observation each for the polluting sector and non-polluting sector of the manufacturing industry in that particular county/year. Second, I compute the average "cohort" earnings by collapsing the micro data to the cohortxyear. Cohorts are defined by the county and sector of work in 1990. In either model, collapsing the data eases the computational burden while also accounting for issues pertaining to inference when the identifying variation occurs at a more aggregate level (Bertrand, Duflo, and Mullainathan 2004).

A more subtle reason for aggregation in this particular context is due to biases induced by selective attrition in log earnings models. I estimate log earnings regressions since I do not have an accurate measure of the costadjusted, real wage for each labor market over time. When estimating models using log earnings, any cohort-year

\footnotetext{
${ }^{23}$ Note that these permits are simply operating permits that the EPA requires polluting plants obtain to legally emit pollutants. These permits are unrelated to "cap and trade" permits from other pollution abatement programs, in that they are non-tradable and are fixed for a particular source.

${ }^{24}$ In a companion paper, Walker (2011) uses the AFS linked to the LBD to examine how CAA regulatory status affects plant-level gross job flows.
} 
in which all individuals are unemployed will drop out of the regression sample (i.e. $\log (0)$ is undefined). Therefore, more granular definitions of cohorts leads to selective attrition from the sample. ${ }^{25}$ Accordingly, I aggregate to minimize this type of selective attrition. Estimates using more granular group definitions yield similar results.

\subsection{Baseline Industry and Worker Characteristics}

Table 1 presents characteristics of the data in terms of plant, worker, and sectoral characteristics. The columns are indexed first by county (i.e. attainment, nonattainment, and those that switch into nonattainment following the CAAA of 1990) and then by the polluting/non-polluting sector. Since this table presents statistics only from 1990, the sample only consists of the manufacturing sector. As workers move from their initial 1990 employer, gradually other industries work their way into the analysis. When comparing polluting to non-polluting sectors in Panel A, it becomes immediately clear that polluting plants tend to be older and larger than their non-polluting counterparts. This distinction becomes important when comparing worker outcomes across these groups, as younger and smaller firms experience both faster growth (Dunne, Roberts, and Samuelson 1989) and tend to pay higher earnings conditional on size (Schmieder 2010).

Turning to Panel B of Table 1, we see that workers in the polluting sector are paid considerably more than their non-polluting counterparts. There are several reasons why workers in the polluting sector may be paid more such as higher rates of unionization, compensating wage differentials pertaining to worker health, and/or any skill differentials in the production process. This last point can be see when comparing education across polluting/non-polluting sectors. Workers in the polluting sector are, on average, older and more educated than their non-polluting counterparts.

Table 1 highlights two of the major forms of selection that need to be accounted for in any research design evaluating the differences in earnings profile across these groups. Younger firms tend to pay higher wages, and they experience higher separation rates relative to their older counterparts. In contrast, workers in the polluting sector tend to be older and more educated, leading them to have higher earnings. The primary research design relies upon within sector comparisons before and after the changes in regulatory status. Accordingly, the main source of identifying variation comes from within Column 6 of Table 1, which constitutes the polluting sector in counties that switched into nonattainment following the CAAA of 1990. The exact details pertaining to estimation and identification are described in the following section.

\footnotetext{
${ }^{25}$ Selective attrition is exacerbated by the dynamic nature of the estimation framework. In the distributed lag models estimated in this project, if a cohort has zero earnings in any lagged year, the entire cohort drops out in every year the zero earnings lagged variable remains in the model. These issues are dramatically reduced by using more aggregate cohort definitions (i.e. county $\times$ sector). In the main specification, any worker with missing earnings for a given year simply does not contribute to the cohort average in the year they are missing, whereas in the case of models which replace non-employment with zero earnings, these workers will lower the respective cohort average earnings in that year.
} 


\section{Measurement Framework}

\subsection{Estimation Setup: A Two Period Example}

The estimation strategy is first illustrated in a two period example and then extended to incorporate dynamics. There are three margins of variation inherent in this empirical framework: county nonattainment status $(c \in$ Attain, Nonattain), polluter status ( $s \in$ Polluting, Non-Polluting), and two time periods ( $\tau \in$ Pre, Post). EPA regulations apply only to polluting firms in nonattainment counties after the nonattainment designation goes into place. Let $N_{c}$ be an indicator equal to 1 for counties that were newly designated as nonattainment. Let $P_{s}$ be an indicator for the polluting sector, and let $1\left(\tau_{t}>0\right)$ be an indicator for the years after the introduction of the new regulations. Then $N_{c} \times P_{s} \times 1\left(\tau_{t}>0\right)$ is an indicator equal to 1 for those sectors that change regulatory status with the introduction of the 1990 CAAA (i.e. polluting sectors in newly designated nonattainment counties after the change in regulation). This term will serve as the reduced form proxy corresponding to the regulations induced by nonattainment designation in the econometric model described below.

Consider the data generating process for outcome $Y_{\text {cst }}$ (i.e. earnings and employment) in the unregulated county-sectors

$$
Y_{c s t}=\rho_{c s}+\gamma_{t}+n_{c t}+p_{s t}+\epsilon_{c s t}
$$

where $\rho_{c s}$ are county $\times$ sector indicators meant to model time invariant observed or unobserved characteristics that govern outcome $Y_{c s t} ; \gamma_{t}$ are year fixed effects to capture overall trends in outcomes; $n_{c t}$ is a vector of nonattainment $\times$ year effects to model aggregate shocks common to nonattainment counties in a given year; and $p_{s t}$ is a vector of polluting sector $\times$ year fixed effects. The error, $\epsilon_{c s t}$, represents unobserved county $\times$ sector shocks to outcomes that would have occurred in the absence of treatment so that

$$
E\left[\epsilon_{c s t} \mid \rho_{c s}, \gamma_{t}, n_{c t}, p_{s t}\right]=0
$$

The change in $Y_{c s t}$ due to a change in a county $\times$ sector's nonattainment designation may be inferred from the coefficient on $\eta_{1}$ in the equation below:

$$
Y_{c s t}=\eta_{1}\left[N_{c} \times P_{s} \times 1\left(\tau_{t}>0\right)\right]+\rho_{c s}+\gamma_{t}+n_{c t}+p_{s t}+\epsilon_{c s t}
$$

where $\eta_{1}$ represents the reduced-form effect of nonattainment designation on outcome $Y_{\text {cst }}$. Equation (2) is simply a difference-in-difference-in-difference estimator of the change in outcome $Y_{\text {cst }}$ attributable to changes in nonattainment designation for polluting sectors. For this estimate to be unbiased, outcome $Y_{c s t}$ must depend 
additively on these unobserved factors. The identifying assumption is that there are no other factors generating a difference in differential trends between production decisions in regulated and unregulated manufacturing firms.

While the identifying assumption of these models is untestable, data from other time periods and alternative specifications permit several indirect tests. First, data from years prior to the change in regulations permit the analysis of trends in covariates and outcomes prior to the change in policy. Second, since regulations in the polluting sector may lead to indirect effects on workers outside the polluting sector, an alternative specification provides a test as to the importance of these spillovers in contributing to bias in relative earnings comparisons. Since nonattainment designation varies at the county level, models which estimate earnings changes for all manufacturing workers in a county (i.e. workers in both the polluting and non-polluting sector) will encompass both the direct regulatory induced wage effects as well as any indirect local spillover effects in the unregulated manufacturing sector. This test is given by the difference-in-difference estimator:

$$
Y_{c t}=\eta_{G}\left[N_{c} \times 1\left(\tau_{t}>0\right)\right]+\rho_{c}+\gamma_{t}+\epsilon_{c t} .
$$

This test relies on the assumption that employment spillovers are important within a county but are not important across counties. Since the LEHD offers information on location and industry of any subsequent jobs, it is possible to observe the magnitudes of within-county versus across-county transitions, informing the strength of this assumption. If labor market spillovers into other markets do not appreciably affect the wages in those sectors, either due to inelastic labor demand or imperfectly competitive wage-setting, the estimate of equation (3) should be exactly proportional to the size of the polluting sector in newly regulated counties. That is, $\hat{\eta}_{G}$ from equation (3) should be equal to $\hat{\eta}_{1}$ from equation (2) times the fraction of workers in the polluting sector of newly regulated counties.

\subsection{A Cohort-Based Approach}

If labor markets are geographically integrated, fully competitive, and in continuous equilibrium, then all worker transitions are voluntary, and examining changes in average sectoral earnings in this setting would be sufficient for estimating regulatory incidence. However, frictions in the labor market and involuntary job transitions imply that industry earnings may not fully characterize the effects of innovations in labor demand on the affected workforce. As the theoretical discussion in Section 3 suggests, ex-post industry earnings may also be subject to composition biases from non-random worker exits.

One possible solution to these issues is to follow the same group of workers over time, explicitly observing both the earnings costs associated with reductions in average sectoral productivity as well as any future earnings costs associated with transitions between jobs. This is the approach taken in this paper. Specifically, I group 
workers based upon their sector and location of work in the year prior to the 1990 CAA Amendments. I then follow these groups over time, allowing workers to change both industries and locations while still contributing to their "cohort's" earnings. The cohort earnings then explicitly nests both the earnings costs associated with reductions in sectoral productivity in the newly regulated sector with any earnings costs associated with job transitions for workers who leave the sector. Formally, I modify equation (2) to estimate changes in the cohort wage

$$
\tilde{Y}_{c s t}=\eta_{1}\left[\tilde{N}_{c} \times \tilde{P}_{s} \times 1\left(\tau_{t}>0\right)\right]+\tilde{\rho}_{c s}+\gamma_{t}+\tilde{n}_{c t}+\tilde{p}_{s t}+\tilde{\epsilon}_{c s t}
$$

where a tilde represents a cohort-specific variable, and the subscripts $c$ and $s$ correspond to the original county and sector from which that cohort originated.

\subsection{Estimation Setup: Incorporating Dynamics}

I generalize equations (2) and (4) to allow the regulatory changes to evolve incrementally:

$$
\begin{aligned}
& Y_{c s t}=\sum_{k=-5}^{10} \eta_{1}^{k}\left[N_{c} \times P_{s} \times 1\left(\tau_{t}=k\right)\right]+\rho_{c s}+\gamma_{t}+n_{c t}+p_{s t}+\epsilon_{c s t} \\
& \tilde{Y}_{c s t}=\sum_{k=0}^{10} \eta_{1}^{k}\left[\tilde{N}_{c} \times \tilde{P}_{s} \times 1\left(\tau_{t}=k\right)\right]+\tilde{\rho}_{c s}+\gamma_{t}+\tilde{n}_{c t}+\tilde{p}_{s t}+\tilde{\epsilon}_{c s t}
\end{aligned}
$$

Equations (5) and (6) are simply generalizations of a triple-difference estimator that allows any regulatory effects to evolve over time as opposed to assuming that the effect occurs immediately and lasts forever. Equation (5) examines the dynamic relationships between regulatory changes, employment and sectoral earnings using data from the LBD for the years 1985-2000. Equation (6) explores how results differ when using cohort-specific outcomes (i.e. earnings, job separation rates, and non-employment durations) using data from the LEHD from for the years 1990-2000. ${ }^{26}$ These two equations serve as the principal econometric framework for the rest of the empirical analysis.

A few final estimation details bear mention. First, estimates using the LBD (employment and industry earnings) rely on samples for every year from $\tau=-5$ to $\tau=10$, whereas the LEHD samples (cohort earnings) are limited to work histories from $\tau=-1$ to $\tau=10$. Because the LEHD begins in the year prior to the change in regulations, this is the earliest period for which worker earnings records exist. Second, cluster-robust standard

\footnotetext{
${ }^{26}$ In theory, since nonattainment designations are pollutant-specific, it is possible to jointly estimate the pollutant-specific effects of nonattainment status (Greenstone 2002). In practice, this is difficult due to the dynamic nature of the estimation strategy and the large number of parameters for each pollutant class. Specifically, for each pollutant there are 45 parameters to be estimated: the baseline triple difference parameters (15), the polluter-by-year fixed effects for each pollutant (15), and the nonattainment-by-year fixed effects (15). Degrees of freedom issues prevent this from being a viable econometric test, although models stratifying by pollutant yield similar estimates to those produced in the baseline estimates below.
} 
errors are used for inference to account for correlation between sectors and cohorts in the same county, both within periods and over time. Third, the specifications are weighted by the sector or cohort employment size in the years before the change in regulations to account for heteroskedasticity associated with differences in group sizes. The weighting specification also ensures that estimates reflect the earnings costs for the average worker as opposed to the average cohort/sector. ${ }^{27}$

\section{Results}

The results are presented in the various subsections below. I begin by examining employment at the industry level (Section 7.1). This is done to motivate the baseline empirical framework by first demonstrating that industry employment measures respond to changes in regulations. Section 7.2 presents the central findings of the paper, consisting of the earnings responses of workers in newly regulated sectors over time. Subsequent sections (Sections 7.3-7.7) offer various robustness checks and explore both the mechanisms generating the observed earnings change as well as heterogeneity in the central estimates.

\subsection{Regulation Leads to a Reduction in Sectoral Employment}

Previous literature has shown that the CAA regulations lead to industry downsizing (Henderson 1996, Greenstone 2002, Kahn and Mansur 2010, Walker 2011). However, these estimates reflect earlier time periods and/or a different sample of states, and it is not clear how previous results generalize into this particular setting. I begin by estimating the degree to which sectoral employment responds to changes in environmental regulations. The focus on sectoral employment rather than plant employment is done so that regression estimates reflect employment flows on both the intensive and extensive plant operating margin. ${ }^{28}$ If reductions in labor demand (and/or labor supply) are costly to the affected workforce, results from this exercise should motivate the incidence analysis using workers' earnings histories. I draw upon the Longitudinal Business Database (LBD) to construct measures of average sectoral employment for each county $\times$ sector from $\tau=-5$ to $\tau=10$.

Figure 3 plots the coefficients from a version of equation (5) using log(employment) as the dependent variable. Specifically, Figure 3a plots event time indicators ( 5 years before and 10 years after) for both the newly-regulated, polluting sector as well as sectors presumed to be unaffected by the direct regulatory variation. The plotted coefficients represent the time path of employment in each sector relative to the year before the change in regulations conditional on county $\times$ sector fixed effects $\rho_{c s}$ and year fixed effects $\gamma_{t}$. In the presence of county $\times$ sector fixed effects not all the event-time indicators are identified. For this reason, I normalize the coefficient on indicators in

\footnotetext{
${ }^{27}$ For samples using the LBD, the weights correspond to sectoral employment in year $\tau=-5$. In samples using the LEHD, the weights correspond to the size of cohort in year $\tau=-1$.

${ }^{28}$ If a plant were to exit in any period $\tau \in[-5,10]$, that plant would drop out of a plant level regression of equation (5). Plant level models yield results similar to those presented here. See Walker (2011) for further plant level evidence.
} 
$\tau=-1$ to be equal to zero. Figure $3 \mathrm{~b}$ plots the difference between the solid line and dashed lines in Figure 3a, which corresponds to the "triple-difference" coefficient estimates from equation (5). ${ }^{29}$

There are two important features from Figure 3. First, employment in years prior to the change in regulations is nearly constant and not significantly different from zero. The lack of significant employment effects in the years prior to the change in policy provide an important test as to the validity of the identifying assumption; trends in outcomes across comparison groups evolve smoothly except through the change in policy. The second important feature of Figure 3 is that beginning with the year of the regulatory change, employment of polluting sectors in newly regulated counties begins to fall, reaching levels nearly 10 percent below 1990 employment levels in the 5 years after the regulatory change (or 15 percent below the counterfactual employment trends). ${ }^{30}$ The magnitudes and dynamics of the estimates are similar to those of Walker (2011), which uses the same dataset for the entire United States rather than this restricted subsample. See Walker (2011) for further discussion of these results as they pertain to plant and sectoral job destruction and job creation rates.

\subsection{The Wage Costs of Sectoral Reallocation: Evidence from Cohorts}

Previous research and the conceptual framework suggest that industry wages are not sufficient for characterizing the incidence of labor market reallocations for two reasons: (i) composition biases may affect average industry wage measures, and (ii) changes in wages do not reflect the costs born by those workers who switch sectors. Here, I present the results using cohort earnings, where cohorts are defined by the place of work in year $\tau=-1$. By following the same group of workers over time before and after the changes in regulations, the composition of the workforce remains constant and any future earnings losses (or gains) associated with job transitions are incorporated into the earnings measure.

Table 2 presents the central findings of the paper using cohort earnings as the dependent variable in various versions of equation (6). Each column in the table corresponds to a different regression. Columns (1)-(4) report exponentiated coefficients from equation (6) using the translation $\exp \left(\eta_{1}^{k}-1\right)$. Column (1) suggests that new environmental regulations lead to a reduction in earnings for the cohort affected by the regulations. The earnings decrease steadily over time, beginning to level off after three years, at which point they begin to recover to their pre-regulation level. The last row of Table 2 presents estimates of the total present discounted value of the earnings change over the 9 reported years, discounting the future earnings changes using a 4 percent annual discount rate. ${ }^{31}$ After 9 years the average worker in the affected cohort experienced a present discounted

\footnotetext{
${ }^{29}$ Specifically, Figure $3 \mathrm{~b}$ plots the $\hat{\eta}_{1}^{k}$ coefficient estimates from equation $(5)$ after controlling for county $\times$ sector, polluting-sector $\times$ year, nonattainment $\times$ year, and year fixed effects.

${ }^{30} \mathrm{An}$ auxiliary test of the slopes in Figure 3, before and after regulation, rejects the null of equal slope with a $\mathrm{p}$ value of 0.03 .

${ }^{31}$ Specifically, this is calculated as $\sum_{k=0}^{8} \beta^{k}\left(\exp \left(\eta_{1}^{k}\right)-1\right)$, where $\beta^{k}$ is the discount factor corresponding to a 4 percent annual discount rate.
} 
earnings loss of around 26.1 percent of their pre-regulatory earnings. Note that these estimates do not condition on job separation and thus are a weighted average of earnings changes for those workers who leave the sector and those workers who stay.

Column (2) of Table 2 includes controls for the average experience of the cohort in a given year. ${ }^{32}$ While including cohort fixed effects will control for mean differences in earnings across these sectors, they do not account for differences in the growth rate of earnings across the various groups. Thus, a linear and quadratic term in potential experience is meant to capture some of this heterogeneity across cohort earnings profiles in the spirit of Mincer (1974). Controlling for average cohort experience reduces the size of the estimated effect slightly, but the 9 year present discounted value still exceeds 22 percent of pre-period earnings. Column (3) adds a common trend for earnings in each cohort county. ${ }^{33}$ Here, estimates are identified by comparing earnings changes before and after the policy, after netting out any earnings trends common to both the polluting and non-polluting sector of a given "county cohort". The results remain very similar the estimates from column (2). Column (4) includes county $\times$ year fixed effects, so that the identifying variation comes from pairwise comparisons of cohort earnings for workers who were in either the polluting or non-polluting sector of a newly regulated county in the years before the policy. These estimates tend to be smaller than the estimates in columns (1)-(3), which may be driven by local spillovers or through measurement error and the resulting attenuation bias from a misspecified regulatory variable. The issue of local spillovers will be addressed in subsequent sections.

Column (5) of Table 2 presents estimates where the dependent variable has been replaced with the average cohort earnings (as opposed to log earnings), and the results are similar to both columns (2) and (3). The present discounted earnings loss amounts to $\$ 8477$, which is 22 percent of the average earnings for workers in the polluting sector of switching counties (i.e. Column 6 of Table 1). Lastly, Column (6) presents estimates from models that replace any missing earnings observations with zeros. Recall that the baseline estimates ignore any missing annual earnings when calculating the average cohort earnings (i.e. up to three quarterly earnings can be missing per year). Since missing earnings may occur through either unemployment or sample attrition, it is not a priori clear how to address such an issue. ${ }^{34}$ To understand the implications of missing earnings in my data, I replace any annual earnings data that is missing with a zero, conditional on that worker having positive earnings in the final year of the data. In theory, this should serve as a lower bound on earnings estimates as we are attributing all sample attrition to unemployment rather than other worker transitions (such as moving to non LEHD states or switching into self-employment).

Appendix Table B.2 presents results using two alternative earnings measures. The first measure (columns (1)-

\footnotetext{
${ }^{32}$ Sectoral experience is proxied by "potential experience" which is defined here as: average sectoral age - average sectoral education $-6$.

${ }^{33}$ Recall that cohorts are defined by the 1990 county $\times$ sector. Thus, the "county trend" in Table 2 corresponds to a trend for each 1990 "county cohort".

${ }^{34}$ This issue is not unique to this paper, and other papers have dealt with these limitations in similar fashions. See e.g. Jacobson, LaLonde, and Sullivan (1993).
} 
(2)) replaces any missing earnings in a worker's earnings history with their last observed earnings. In contrast to filling missing earnings observations with zero, these results should serve as a useful upper bound on the absolute magnitude of the earnings losses. The estimates are indeed smaller in magnitude than those from Table 2, but earnings losses still remain more than 19 percent of the pre-regulatory earnings. Columns (3)-(4) present results from a sample that consists only of workers that had non-missing earnings observations in every year of the sample. This selection criteria mimics that employed by Jacobson, LaLonde, and Sullivan (1993) in their seminal paper on mass layoffs and the cost of job loss. This selection criteria results in a different sample of workers, but the results remain fairly similar. The main difference between this sample and the baseline sample is that it excludes cohorts for which all workers were unemployed for at least one year in the data. This selective attrition occurs primarily for small cohort sizes (i.e. rural areas) and is reflected in the heterogeneity of the estimates. $^{35}$

A useful feature of these estimates is that they permit a direct monetization of regulatory costs in terms of foregone earnings. The average present discounted earnings loss estimate from Table 2 is around 23 percent of 1990 earnings. Multiplying this number by the average annual earnings in that sector $(\approx \$ 39,000)$ and then by the total number of employees in the polluting sector of all "switching" counties in the United States (approximately 1 million workers), ${ }^{36}$ the total foregone wage bill is approximately 9 billion dollars.

To facilitate interpretation, Figures $4 \mathrm{a}$ and $4 \mathrm{~b}$ present graphical estimates of equation (6). Specifically, the plotted coefficients in Figure 4a are coefficient estimates from a single regression of cohort earnings against event time indicators for various cohorts of workers. Regression estimates control for cohort fixed effects and year fixed effects. The solid line represents the time path of earnings for workers in the newly-regulated, polluting sector, whereas the dashed lines represent the various counterfactual earnings profiles of either polluting sector workers in unaffected counties or non-polluting sector workers in newly regulated counties. Figure 4b corresponds to the regression estimates in Table 2, which are implicitly identified by taking the difference between the solid line and dashed lines in Figure 4a. The results in both figures show the earnings profile of workers in the newly regulated sector falling in the years after the policy change, only beginning to recover after 3-4 years.

Since county level nonattainment is non-linear in the level of pollution, it is possible to estimate models that exploit this non-linearity. Namely, counties that were near to the ambient air pollution, regulatory threshold in the years prior to the policy were not certain ex-ante as to whether the proposed regulations would apply in their county. Therefore, any anticipatory action on the part of the regulator or the firm in the years prior to the regulations is less likely to bias estimates for these threshold counties. In practice, the relatively few number of counties in the four states of this analysis preclude a formal treatment of a regression discontinuity

\footnotetext{
${ }^{35}$ For example, the earnings recovery is more rapid for workers in thicker, urban labor markets reflected in the more rapid earnings recovery in both columns (3) and (4). In addition, the cost of living in more urban areas is also higher, which is reflected in the larger levels estimates from column (4)).

${ }^{36}$ This last statistic comes from Table 1 of Walker (2011).
} 
design. Instead, I adopt the approach taken in Chay and Greenstone (2005) and restrict the sample to counties that are 1 standard deviation above and below the nonattainment threshold. Appendix Figure B.3 presents the earnings estimates for cohorts originating in counties one standard deviation above and below the EPA's ambient air pollution, nonattainment threshold for particulate matter. The dashed line corresponds to the "threshold county" estimates, whereas the solid line plots the baseline cohort earnings estimates for comparison (from Table 2 and Figure 4). This "threshold-county" sample restriction reduces the sample size by 85 percent, but the results remain similar both in terms of magnitude and dynamics. However, the results lose statistical precision.

\section{3 "Local" General Equilibrium Effects}

Any major shift in the sectoral labor supply or demand curves is likely to influence other sectors within the same local labor market. Assuming that polluting sector workers are substitutes across sectors, any workers leaving the polluting sector will increase the potential labor supply of the unregulated sector within that county. If wages are set on a downward sloping demand curve, this increase in the labor supply will drive down the equilibrium wage in that sector. Therefore, relative wage comparisons across these groups may understate the total wage costs.

To get a sense of the empirical magnitude of such effects, first consider the following back-of-the-envelope calculation. Manufacturing accounts for about 15 percent of non-farm employment in the United States, and the polluting sector accounts for a 35 percent share of the manufacturing industry in newly-regulated counties. The employment estimates from Section 7.1 and Figure 3 suggest that employment in newly-regulated sectors falls by around 15 percent in the 5 years after the policy change. This amounts to 0.7 percent of the total employment in newly regulated counties. Using a labor demand elasticity of 0.5 , the implied general equilibrium effect of a 0.7 percent increase in the labor supply would be a 0.35 percent decrease in equilibrium wages for workers in the non-polluting sector of newly regulated counties. This assumes that polluting sector workers are perfect substitutes in all other sectors of the county. Conversely, the other extreme case would occur where workers from the polluting sector transitioned only to the non-polluting manufacturing sector since they may share similar skills. In this case, the same calculation suggests that a reduction in labor demand in the polluting sector would increase labor supply for the non-polluting sector of the manufacturing industry by 8 percent. This would translate into a 4 percent reduction in the equilibrium wages of workers in the non-polluting sector. These two extreme assumptions serve as ex-ante bounds on the importance of local general equilibrium spillovers in the context of the research design.

Alternatively, equation (3) from Section 6.1 offers a straightforward test as to the empirical magnitude of any 
general equilibrium bias present in within-county earnings estimates. ${ }^{37}$ Table 3 presents results from a dynamic version of equation (3) which suggests that the average worker in the manufacturing industry of a county that switched regulatory status experienced a 9.1 percent (discounted) reduction in earnings in the 9 years after the policy change. This consists of the direct earnings effects of workers in the polluting sector and the indirect effects on workers in the non-polluting sector. If there are no general equilibrium wage effects in other sectors then these estimates should be directly proportional to the baseline earnings effects multiplied by the fraction of workers in the polluting sector:

$$
\hat{\eta}_{G}=\left(\frac{N_{\text {Polluter }}}{N_{\text {Total }}}\right) \times \hat{\eta}_{1}
$$

The polluting sector accounts for approximately 35 percent of the manufacturing industry in newly regulated counties, which implies that the right hand side of equation (7) is equal to -8.1 percent. This implies that earnings fell by 0.95 percent in the non-polluting sector of the manufacturing industry for newly regulated counties. ${ }^{38}$ This empirical test relies on the assumption that within-county spillovers are of greater empirical importance than across-county spillovers, but it suggests that the empirical magnitude of these spillovers are small.

\subsection{Mechanisms: Regulation Increases the Rate of Separations}

Presumably, the change in earnings is related to both reductions in sectoral productivity and/or costly job transitions. The subsequent empirical sections attempt to shed light on the mechanisms by which these changes occur, examining gross job flows and earnings changes associated with various labor market transitions.

Since sectoral employment from the LBD only measures net changes in employment, I turn to the LEHD data to estimate the degree to which changes in environmental regulations lead to excess labor reallocation in the years following the policy. ${ }^{39}$ I begin by examining the rate of separation from a worker's "base-year" employer,

\footnotetext{
${ }^{37}$ Instead of the baseline triple-difference estimator from before, I use a difference-in-differences estimator to look at variation in county earnings profiles of all manufacturing workers over time. The model then delivers estimates of the average change in earnings for workers in the manufacturing industry of a county that switched into nonattainment with the introduction of the 1990 Clean Air Act Amendments. If a reduction in labor demand in the polluting sector drives down the equilibrium wage in the non-polluting sector of the same county, then estimates focusing on across-county variation rather than within-county variation will be attenuated by these "local" general equilibrium wage effects.

${ }^{38}$ To see this formally, denote the difference-in-difference earnings estimate for workers in the polluting sector of a newly regulated county as $\hat{P}$. Denote the difference-in-difference earnings estimate for workers in the non-polluting sector of a newly regulated county as $\hat{N}$. The empirical estimate of $\hat{\eta}_{G}$ is a combination of these two terms:

$$
\hat{\eta}_{G}=\left(s_{p} \times \hat{P}\right)+\left(s_{n} \times \hat{N}\right)
$$

where $s_{p}$ and $s_{n}$ reflect the shares of workers in each of these sectors (i.e. $s_{n}+s_{p}=1$ ). Assuming that any across-county wage spillovers are zero, then a triple difference estimate of the earnings impact of regulations on polluting sector is given by $\hat{\eta}_{1}=\hat{P}-\hat{N}$. This implies that

$$
\hat{N}=\hat{\eta}_{G}-\left(s_{p} \times \hat{\eta}_{1}\right)=-0.09-(0.35 \times-0.23)=-0.0095
$$

${ }^{39}$ The employment results from Section 7.1 suggest that some of the earnings changes are associated with reductions in labor
} 
and thus the following discussion parallels that of duration analysis, where a failure in this model is defined by a

separation from the "base-year" firm. ${ }^{40}$ Separation rates for a cohort are calculated at the county $\times$ sector level as the number of "base-year" firm separations in a cohort-year over the total number of workers in that cohort that remain at their pre-regulatory establishment. The data is constructed so that workers contribute to the cohort-year observation for every year they remain with their "1990" plant. The risk set evolves over time as workers leave their 1990 plant.

The empirical analysis estimates how this failure rate changes as a function of the new environmental regulations. The regression framework is the same as used in equation (6), where the dependent variable is the failure rate for workers remaining at their 1990 "pre-regulation" firm. Given the definition of a job separation, there are a positive number of separations in the "base-year". The baseline estimates then measure the differences in the failure rate as a function of the change in regulatory status. Figure 5 plots estimates of the $\eta_{1}^{k}$ 's from equation (6), which corresponds to the difference in the failure rate for the newly regulated sector relative to the year prior to the nonattainment designation. Accompanying Figure 5 is a bar graph representing the fraction of workers in polluting plants of newly designated nonattainment counties that remain in their 1990 firm $t$ years after the CAA Amendments (i.e. the Kaplan-Meier survival probability). The figure shows that the rate of separation increases for the newly regulated cohort in the years following the regulations. After 4 years, the failure rate begins to peak, and after 8 years it is nearly back to the baseline level. Similar to the sectoral employment regressions from before, the estimates here suggest that the changes in regulations lead to a relative reallocation of labor away from the newly regulated sector.

\subsection{Regulation Increases the Incidence of Non-Employment Between Jobs}

Alternatively, we can directly estimate the duration between jobs by looking at the average incidence of nonemployment for a cohort as a function of changes in regulatory stringency. Non-employment is defined as the number of quarters for which a worker has missing earnings in a given year, bounded below by 0 and above by 4 . Appendix Table B.3 summarizes the results from a regression using the average quarters of nonemployment as a dependent variable in equation (6). While the temporal dynamics match those from the earnings estimates and the separation hazards presented above, the results are only marginally significantly different from zero. Taken literally, however, the estimates suggest that the average duration of non-employment increased by 0.35 quarters following the introduction of the regulations. Using this result, we can calculate the earnings loss attributable to non-employment versus earnings losses attributable to future employment at lower wages. This exercise should

demand. However, this tells us little about whether reductions in labor demand cause earnings to fall from the standpoint of reducing the equilibrium wage in the newly regulated sector or by causing costly job transitions from that sector.

${ }^{40} \mathrm{~A}$ job separation is defined as equaling one in period $t$ if earnings $>0$ at plant $j$ in period $t$ and either earnings $=0$ in period $t+1$ or plant $_{j_{1990}} \neq$ plant $_{j_{1990} t+1}$ 
be interpreted as more speculative since the earnings in periods before and after non-employment may also be lower due to a reduction in the total amount of time spent working in the respective quarters. Even so, these estimates suggest that about $38 \%$ of the observed earnings changes are driven by non-employment. ${ }^{41}$

\subsection{Effects of Regulations for "Stayers" and "Leavers"}

While the temporal dynamics from job separations and non-employment incidence parallel those from the cohort earnings (i.e. Figure 4b), it is still not clear what proportion of the observed change in earnings is explained by costly job transitions relative to reductions in sectoral productivity. Here, I examine earnings changes for workers that remain with their initial employer and for workers who separate from their initial employer. As the theoretical discussion in Section 3 suggests, these groups will be self-selected based on sector-specific ability. However, the form of selection has relatively clear predictions for the direction of bias in each of the regressions that I will highlight below. To address the issue of selection bias explicitly, I look at wage changes for only the "stayers" and only the "leavers" in separate models. This allows the inclusion of group-specific fixed effects to isolate the source of identifying variation to come from within each of these groups, before and after the change in policy. By including group-specific fixed effects, the regression model implicitly controls for any time-invariant unobservable characteristics of these "stayers" or "leavers". ${ }^{42}$

I stratify the treatment group based on whether the worker stayed with their firm or separated at some point within the first 4 years after the regulations. ${ }^{43}$ In each specification, I decompose the earnings for the affected cohort only. That is, the earnings of the various control group cohorts remain the same as in the previous section, while the newly regulated sector's earnings consists only of "stayers" or only of "leavers", depending upon the specification. ${ }^{44}$ Column (1) of Table 4 presents results from a version of equation (6) where I compare earnings trends in earnings of the affected cohort only if they remain at their "base-year" firm for more than 4 years after the change in regulations (i.e. they remain at their firm for at least the years $\tau \in[0,4]$ ). The results from column (1) suggest that the earnings of "stayers" are essentially unaffected by the regulatory change. This finding of zero wage response for those who remain at their firm is consistent with previous literature examining wage responses to labor market shocks in the manufacturing industry (Blanchard and Katz 1992, Autor, Dorn, and Hanson 2011, Ebenstein, Harrison, McMillan, and Phillips 2011). This result is also consistent with industrylevel earnings responses. Appendix Figure B.2 plots the average earnings per worker in the newly-regulated,

\footnotetext{
${ }^{41}$ The observed increase in non-employment is around 0.35 quarters (i.e. approximately 1 month in a year). Using the average annual earnings in the polluting sector of counties that switch nonattainment (i.e. Column (6) of Table 1), this amounts to $\$ 3250$ in foregone earnings. This is $38 \%$ of the estimated total earnings loss in Column (4) of Table 2.

${ }^{42}$ This is equivalent to the identifying assumption in the large literature on the cost of job loss stemming from mass layoffs (Jacobson, LaLonde, and Sullivan 1993, von Wachter, Song, and Manchester 2009).

${ }^{43}$ The choice of focusing on workers with separations within 4 years is somewhat arbitrary. However, the results are not sensitive to this cutoff.

${ }^{44} \mathrm{An}$ alternative comparison that gets around this form of selection bias is to compare the earnings of stayers to that of stayers in other sectors. Results (not reported) are consistent with those shown here.
} 
polluting sector before and after the change in regulations using data from the LBD. The figure shows no significant industry earnings response to regulatory changes. While previous research often cites composition bias as one potential reason behind this zero result, the results in Table 4 suggest that composition bias is not the answer (since the composition is constant by construction). One explanation for these results is that union wages are often set in multi-year contracts, making manufacturing wages less sensitive to external shocks in the short/medium run (Lewis 1963).

Column (2) of Table 4 presents the same model as above, except that I examine earnings changes for those who separate from their "base-year" firm in the 4 years after the change in regulations. Here we see much larger earnings changes that are all statistically significant. The pattern of the estimates suggests that the average earnings declines rapidly in the years following the change in regulations, and they begin to recover only in the later years. The present discounted earnings change for separators is more than 130 percent of their pre-regulatory, annual earnings. ${ }^{45}$

In general, the earnings loss attributable to job separations in this context is smaller than estimates found in the literature on displacement induced by mass layoffs (Jacobson, LaLonde, and Sullivan 1993, von Wachter, Song, and Manchester 2009). Notably, the earnings recovery of the average worker in this setting is more rapid than that found in the displacement literature. There are a few possible explanations for these discrepancies. First, it seems possible that the rapid earnings recovery comes from the fact that most of these regulations occur in dense, urban labor markets. Workers are likely able to re-integrate themselves into the workforce more quickly in these "thicker" labor markets than elsewhere where alternative job options are limited (Marshall 1920). Second, it is possible that some of the job transitions I observe are voluntary, job-to-job transitions for which workers often experience a rise in earnings (Bjelland, Fallick, Haltiwanger, and McEntarfer forthcoming). In contrast, the job transitions from mass layoffs are often characterized by involuntary job loss and prolonged unemployment durations (Jacobson, LaLonde, and Sullivan 1993, Davis, Faberman, and Haltiwanger 2006, von Wachter, Song, and Manchester 2009). Third, the rapid earnings recovery may be unique to this setting, stemming from the high-pressure labor market in the mid to late 1990's (Katz, Krueger, Burtless, and Dickens 1999). Lastly, an alternative explanation for this relatively quick recovery comes from the difference in research designs and research questions. Namely, the long run implications from job loss for those who were affected by mass layoffs may be fundamentally different from those affected by the more gradual sectoral changes that we see in this setting.

\footnotetext{
${ }^{45}$ Another estimate of the average cost of job transitions comes from "scaling" the baseline cohort earnings regressions (i.e. column (3) in Table 2) by the number of workers we see transitioning out of that sector (i.e. figure 3). The average sectoral earnings loss for a cohort from Table 2 is around 23 percent. Estimates from figure 3 suggest a more than 15 percent reduction in the sectoral workforce in the 5 years after the policy. This suggests that the average earnings loss for a worker who loses his/her job because of the policy shock is around 150 percent of their 1990 earnings. This is consistent with what we see for those who separate from his/her job in column (2) of Table 4.
} 


\subsection{Sectoral Transition Rates and the Wage Costs of Labor Reallocation}

The ability to follow workers over their employment histories allows for decompositions of worker transitions based on destination sectors. This offers some degree of insight as to how workers respond to sector-specific shocks of this nature. Similar to before, I estimate how the "failure rate" responds to changes in regulations, where a failure is defined as a job separation from the "base-year" firm to a specific location and/or industry. Figure 6 presents these estimates for workers who transition to a different industry in a different county (panel 6a), the same industry in the same county (panel 6b), a different industry in the same county (panel 6c), and the same industry in a different county (panel 6d). The figures suggest that workers in newly regulated sectors are disproportionately more likely to exit to a completely different industry after the regulations, relative to before. Furthermore, workers are more likely to transition to a different industry within the same county.

There is considerable heterogeneity in earnings estimates based on this same set of destination industrylocations. I decompose the earnings effects of separators (i.e. column (2) of Table 4) based on the location and sector where workers in the newly regulated sector find their subsequent job. The estimates suggest that the earnings changes for workers who stay within the same industry and the same county (column (3) of Table 4) are significantly less than for those workers that change industries (even within the same county - i.e. column (4) of Table 4). This is consistent with previous literature suggesting a role for industry-specific human capital as a barrier to job mobility (Podgursky and Swaim 1987, Topel 1991, Neal 1995). Of course, these earnings losses also reflect losses due to non-employment between jobs that may also be higher for workers who switch industries (Murphy and Topel 1987). Figure B.4 displays the estimates from columns (3)-(6), summarizing the dynamics and incidence by destination sectors.

\section{Interpretation and Discussion}

\subsection{The Economic Costs of Sectoral Reallocation}

If workers are paid their marginal product and firms earn zero profits, then all earnings losses are social costs, and the estimates allow for simple approximations of the welfare costs pertaining to policy-induced job reallocation. Throughout, I have made several simplifying assumptions: utility is linear in earnings, workers do not value leisure, and there are no government transfers in the form of unemployment insurance. Under these assumptions, the total foregone wage bill associated with industry reallocation represents the welfare costs to workers.

These are obviously strong assumptions, but they also provide a useful benchmark for assessing the degree to which the estimates presented here serve as upper or lower bounds on the true reallocative incidence. For example, if individuals have concave utility and are liquidity constrained then the welfare losses from unemployment might be much larger than what is implied by mean earnings losses. If workers value leisure, these estimates will 
overstate the welfare costs to workers.

In terms of aggregate welfare and the social costs of workforce reallocation, it is important to realize that, in the United States, workers are often compensated for involuntary job loss in the form of unemployment insurance (UI). ${ }^{46}$ In this case, UI primarily reflects income redistribution among citizens via taxation and transfers and should not be treated as an economic loss, except through the shadow cost of public funds or the deadweight loss of taxation. Consider the following thought experiment pertaining to UI payments in the context of this particular setting. ${ }^{47}$ Average UI payments consist of 20 weeks of compensation at $50 \%$ replacement. Assuming that 150,000 jobs were lost (based on a $15 \%$ reduction in sectoral employment multiplied by the number of workers in the polluting sector of newly regulated counties), this implies an increase in UI payments of approximately $\$ 1.2$ billion. $^{48}$ Then using an estimate of $40 \%$ for the deadweight loss of taxation from Gruber (2010), the economic costs associated with this increase in UI payments amounts to $\$ 480$ million. In such a case, the total economic loss to society associated with CAAA-induced labor reallocation amounts to $\$ 9.48$ billion. ${ }^{49}$

\subsection{Costs Relative to Benefits and Policy Prescriptions}

The EPA estimates the present discounted value (in terms of health benefits) of the 1990 Clean Air Act Amendments from 1990-2010 to be between 160 billion and 1.6 trillion dollars (1990\$) (Environmental Protection Agency 1999). ${ }^{50}$ The lower bound estimate is similar to the estimated benefits from various hedonic studies which estimate marginal willingness to pay for improvements in air quality (see e.g. Chay and Greenstone (2005) and Bayer, Keohane, and Timmins (2009)). In light of these benefits, the transitional costs of worker reallocation are relatively small. In addition, there are reasons to believe the estimates presented in this paper serve as an upper bound on the labor market costs of environmental regulations to workers; namely I have attributed zero value to leisure and the costs of job loss in the early 1990's may be larger than earnings losses in more expansionary time periods. ${ }^{51}$

Obviously, there are many more economic costs associated with the regulations, notably plant productivity effects (Greenstone, List, and Syverson 2010), losses to foreign direct investment (Hanna 2010), as well as

\footnotetext{
${ }^{46}$ Displaced workers may also receive other forms of social assistance such as Social Security Disability Insurance and other forms of government transfers not considered in the following thought experiment.

${ }^{47}$ Social insurance programs such as UI generally redistribute income from those with low marginal utility of income to those with high marginal utility of income. In this simplified, linear-utility setting, the marginal utility of income is constant and thus the following discussion is simply descriptive.

${ }^{48}$ This number is calculated by multiplying average earnings $(\$ 39,000)$ by the $50 \%$ replacement rate for 20 weeks and then times the reduction in employment in the newly regulated sector.

${ }^{49}$ This is calculated as the total foregone wage bill + deadweight loss of taxation associated with UI transfers. This calculation stems from a linear utility assumption (i.e. workers have constant marginal utility of income). In an economy where income is redistributed from individuals with low marginal utility of income to individuals with high marginal utility of income the social value of UI may be positive.

${ }^{50}$ Note that these estimates do not include the estimated benefits from the $\mathrm{SO}_{2}$ trading markets, which are not analyzed in this study.

${ }^{51}$ See Davis and von Wachter (forthcoming) for recent evidence of the cost of job loss over the business cycle. That long-term
} 
any adjustment costs associated with reallocating the capital stock (Goolsbee and Gross 1997, Ramey and Shapiro 2001). ${ }^{52}$ While the results here suggest that the adjustment costs in terms of labor reallocation are relatively small in magnitude compared to the estimated benefits of the policy, workers in these industries are still adversely affected. Accordingly, the EPA included a component of transition assistance in the 1990 CAAA under the Clean Air Employment Transition Assistance Program administered by the Department of Labor. This program was designed to aid workers who were displaced by environmental regulations and was allocated $\$ 50$ million for the 1990 CAAA. Estimates here suggest this program was severely underfunded in terms of compensating workers for any earnings losses pertaining to regulatory induced reallocation.

\section{Conclusion}

This paper makes three primary contributions. First, the estimates document that the reallocative costs of environmental policy in the context of worker outcomes is significant. The average worker in a newly regulated plant experiences a present discounted earnings loss of around $23 \%$ of their pre-regulatory earnings. In aggregate, this amounts to almost $\$ 9$ billion in foregone earnings. Prior research on the labor market impacts of environmental regulation has primarily focused on employment losses in manufacturing industries, without regard for how quickly and at what costs workers are reallocated back into the labor market. The results presented here suggest that the predominant focus of the previous literature on employment misses important aspects of labor market adjustment to environmental regulations.

The findings in this paper have important policy implications both for worker compensation in the context of environmental regulations and also more generally in terms of labor market adjustment. The results suggest that firms respond to environmental regulations; costly job transitions from the perspective of the workforce are a consequence of this response. The magnitude of these estimates calls into question the amount of transition assistance allocated under the CAA Amendments of 1990, which was more than two orders of magnitude below what would be needed to fully compensate the affected workforce.

Second, the estimates shed light on how both firms and workers respond to gradual changes in regulatory stringency. Aggregate employment falls in affected sectors, but the wages for workers who remain at the firm do not. Instead, most of the costs of reallocation occur through costly job transitions associated with sectoral downsizing. Job transitions occur mostly from the regulated sector to other industries within the same labor market rather than across labor markets. These findings highlight the importance of longitudinal data for characterizing the costs and consequences of labor market adjustment.

\footnotetext{
${ }^{52}$ While both Goolsbee and Gross (1997) and Ramey and Shapiro (2001) look at the adjustment costs of capital, these studies do not consider capital adjustment costs in the context of environmental regulation. However, this research suggests that these costs may be significant in the context of environmental regulations and suggest an interesting area for future research.
} 
Third, this paper offers a new approach to understanding the costs and consequences of labor market shocks in an economy where labor is not instantly reallocated and average industry wages may not fully reflect shifts in the labor demand curve. By exploiting detailed longitudinal data and following the same group of workers over time, regression estimates correspond to the average change in earnings for workers who stay at their firm and the cost of job transitions for those who leave. In addition, concerns pertaining to compositional biases are explicitly addressed.

The arguments supporting environmental regulations point to increasing evidence that benefits from environmental policy far exceed the costs. The findings in this paper do not contradict this logic; the wage costs borne by workers are a small fraction of the estimated benefits. These findings simply highlight the fact that regulations have distributional consequences - there are both winners and losers. The empirical approach in this paper could be applied to any area concerned with the distributional implications of labor market adjustment, be it cost shocks to firms, local labor demand shocks to economies, trade shocks, or the welfare costs of natural disasters. The one limitation of this approach is the data necessary to implement it. However, with the growing availability of longitudinal micro data, this should be a fruitful area of future research. 


\section{References}

Abowd, J. M., B. E. Stephens, L. Vilhuber, F. Andersson, K. L. McKinney, M. Roemer, and S. Woodcock (2008): "The LEHD Infrastructure Files and the Creation of the Quarterly Workforce Indicators," LEHD Working Paper.

Abraham, K., And J. Medoff (1984): "Length of Service and Layoffs in Union and Nonunion Work Groups," Industrial and Labor Relations Review, pp. 87-97.

Altonji, J., And P. Devereux (1999): "The extent and consequences of downward nominal wage rigidity," .

Arrow, K., M. Cropper, G. Eads, R. Hahn, L. Lave, R. Noll, P. Portney, M. Russell, R. Schmalensee, K. Smith, and R. Stavins (1996): "Benefit-Cost Analysis in Environmental, Health, and Safety Regulation," Washington, DC: American Enterprise Institute, pp. 1-17.

Artuc, E., S. Chaudhuri, and J. McLaren (2010): "Trade Shocks and Labor Adjustment: A Structural Empirical Approach," The American Economic Review, 100(3), 1008-1045.

Auffhammer, M., A. Bento, and S. Lowe (2009): "Measuring the effects of the Clean Air Act Amendments on ambient PM10 concentrations: The critical importance of a spatially disaggregated analysis," Journal of Environmental Economics and Management, 58(1), 15-26.

Autor, D., D. Dorn, And G. Hanson (2011): "The China Syndrome: Local Labor Market Effects of Import Competition in the United States," Working Paper.

Baker, G., M. Gibbs, and B. Holmstrom (1994): "The wage policy of a firm," The Quarterly Journal of Economics, 109(4), 921.

BARTIK, T. J. (1991): "Who benefits from state and local economic development policies?," Books from Upjohn Press.

Bayer, P., N. Keohane, And C. Timmins (2009): "Migration and hedonic valuation: The case of air quality," Journal of Environmental Economics and Management, 58(1), 1-14.

Beaudry, P., D. Green, And B. Sand (2011): "Does Industrial Composition Matter for Wages? A Test of Search and Bargaining Theory," Econometrica, Forthcoming.

BeCKer, R. (2005): "Air pollution abatement costs under the Clean Air Act: evidence from the PACE survey," Journal of environmental economics and management, 50(1), 144-169.

Becker, R., And J. Henderson (2001): "Costs of air quality regulation," in Behavioral and Distributional Effects of Environmental Policy, ed. by C. Carraro, and G. E. Metcalf, pp. 159-186. University Of Chicago Press.

Becker, R., And V. Henderson (2000): "Effects of air quality regulations on polluting industries," Journal of Political Economy, 108(2), 379-421.

Berman, E., AND L. Bui (2001): "Environmental regulation and productivity: evidence from oil refineries," Review of Economics and Statistics, 83(3), 498-510.

Bertrand, M., E. Duflo, and S. Mullainathan (2004): "How Much Should We Trust Differences-inDifferences Estimates?," Quarterly Journal of Economics, 119(1), 249-275.

Bewley, T. (1999): Why wages don't fall during a recession. Harvard Univ Pr.

Bjelland, M., B. Fallick, J. Haltiwanger, and E. McEntarfer (forthcoming): "Employer-to-Employer Flows in the United States: Estimates Using Linked Employer-Employee Data," Journal of Business and Economic Statistics.

Blanchard, O., And L. Katz (1992): "Regional evolutions," Brookings papers on economic activity, pp. 1-75.

BorJas, G. (2003): "The Labor Demand Curve is Downward Sloping: Reexamining the Impact of Immigration on the Labor Market*," Quarterly journal of Economics, 118(4), 1335-1374.

Borjas, G., R. Freeman, and L. Katz (1997): "How much do immigration and trade affect labor market outcomes?," Brookings papers on economic activity, 1997(1), 1-90.

BorJas, G., AND V. RAmeY (1995): "Foreign competition, market power, and wage inequality," The Quarterly Journal of Economics, 110(4), 1075. 
Bound, J., And H. Holzer (2000): "Demand Shifts, Population Adjustments, and Labor Market Outcomes during the 1980s," Journal of Labor Economics, 18(1), 20-54.

Bound, J., And A. Krueger (1991): "The Extent of Measurement Error in Longitudinal Earnings Data: Do Two Wrongs Make a Right?," Journal of Labor Economics, pp. 1-24.

Brown, C., And J. Medoff (1989): "The Employer Size-Wage Effect," The Journal of Political Economy, 97(5), 1027.

Campbell III, C., And K. Kamlani (1997): "The Reasons For Wage Rigidity: Evidence From A Survey Of Firms," Quarterly Journal of Economics, 112(3), 759-789.

CARD, D. (2001): "Immigrant Inflows, Native Outflows, and the Local Labor Market Impacts of Higher Immigration," Journal of Labor Economics, 19(1), 22-64.

Chay, K., And M. Greenstone (2003a): "Air Quality, Infant Mortality, and the Clean Air Act of 1970," NBER Working Paper.

Chay, K., And M. Greenstone (2003b): "The Impact of Air Pollution on Infant Mortality: Evidence from Geographic Variation in Pollution Shocks Induced by a Recession*," Quarterly Journal of Economics, 118(3), $1121-1167$.

$113(2)$.

Congressional Budget Office (2009): "The Economic Effects of Legislation to Reduce Greenhouse-Gas Emissions," .

Copeland, B., And S. TAYlor (2004): "Trade, Growth, and the Environment," Journal of Economic Literature, 42(1), 7-71.

Currie, J., And M. Neidell (2005): "Air Pollution and Infant Health: What Can We Learn from California's Recent Experience?," The Quarterly Journal of Economics, 120(3), 1003-1030.

Davis, S., J. Faberman, and J. Haltiwanger (2006): "The flow approach to labor markets: new data sources and micromacro links," The Journal of Economic Perspectives, 20(3), 3-26.

Davis, S., And T. von Wachter (forthcoming): "Recessions and the Costs of Job Loss," Brookings Papers on Economic Activity.

Deschenes, O. (2010): "Climate Policy and Labor Markets," NBER Working Paper.

Dix-Carneiro, R. (2011): "Trade Liberalization and Labor Market Dynamics," Mimeo.

Duncan, G., AND D. Hill (1985): "An investigation of the extent and consequences of measurement error in labor-economic survey data," Journal of Labor Economics, pp. 508-532.

Dunne, T., M. Roberts, And L. SAmuelson (1989): "The growth and failure of US manufacturing plants," The Quarterly Journal of Economics, 104(4), 671-698.

Ebenstein, A., A. Harrison, M. McMillan, and S. Phillips (2011): "Estimating the Impact of Trade and Offshoring on American Workers Using the Current Population Surveys," Working Paper.

Environmental Protection Agency (1999): "The Benefits and Costs of the Clean Air Act 1990 to 2010," EPA Report to Congress.

— (2005): "Environmental Economics Research Strategy," 600(R-04), 195.

(2008): "National Air Quality-Status and Trends through 2007," .

FEenstRA, R. (2010): Offshoring in the global economy: microeconomic structure and macroeconomic implications. The MIT Press.

Fehr, E., AND L. Goette (2005): "Robustness and real consequences of nominal wage rigidity," Journal of Monetary Economics, 52(4), 779-804.

Friedberg, R., And J. Hunt (1995): "The impact of immigrants on host country wages, employment and growth," The Journal of Economic Perspectives, 9(2), 23-44.

FriJters, P., AND B. VAN DeR KlaAuw (2006): "Job Search with Nonparticipation," The Economic Journal, $116(508), 45-83$. 
Fullerton, D. (2008): "Distributional effects of environmental and energy policy: an introduction," NBER working paper, (W14241).

Gibbons, R., And L. Katz (1991): "Layoffs and Lemons," Journal of Labor Economics, 9(4), 351-380.

Goolsbee, A., And D. Gross (1997): "Estimating adjustment costs with data on heterogeneous capital goods," NBER working paper, (W6342).

Greenstone, M. (2002): "The impacts of environmental regulations on industrial activity: Evidence from the 1970 and 1977 clean air act amendments and the census of manufactures," Journal of Political Economy, $110(6)$.

Greenstone, M., J. List, And C. Syverson (2010): "The Effects of Environmental Regulation on the Competitiveness of U.S. Manufacturing," mimeo.

Gruber, J. (2010): Public Finance and Public Policy. Worth Publishers, 3rd edition edn.

HANnA, R. (2010): "US Environmental Regulation and FDI: Evidence from a Panel of US-Based Multinational Firms," American Economic Journal: Applied Economics, 2(3), 158-189.

Heckman, J., And G. Sedlacek (1985): "Heterogeneity, aggregation, and market wage functions: an empirical model of self-selection in the labor market," The journal of political economy, 93(6), 1077-1125.

Henderson, V. (1996): "Effects of air quality regulation," The American Economic Review, 86(4), 789-813.

Hopenhayn, H. (1992): "Entry, exit, and firm dynamics in long run equilibrium," Econometrica: Journal of the Econometric Society, 60(5), 1127-1150.

Jacobson, L., R. LaLonde, and D. Sullivan (1993): "Earnings losses of displaced workers," The American Economic Review, 83(4), 685-709.

Jaffe, A., S. Peterson, P. Portney, and R. Stavins (1995): "Environmental Regulation and the Competitiveness of U.S. Manufacturing: Environmental Regulation and the Competitiveness of U.S. Manufacturing: What Does the Evidence Tell Us?," Journal of Economic Literature, XXXIII, 132-163.

Jarmin, R., AND J. Miranda (2002): "The longitudinal business database," US Census: Center for Economic Studies, Working Paper.

Jovanovic, B. (1982): "Selection and the Evolution of Industry," Econometrica: Journal of the Econometric Society, 50(3), 649-670.

Kahn, M., And E. Mansur (2010): "How Do Energy Prices, and Labor and Environmental Regulations Affect Local Manufacturing Employment Dynamics? A Regression Discontinuity Approach," NBER working paper, (16538).

Katz, L., A. Krueger, G. Burtless, and W. Dickens (1999): "The high-pressure US labor market of the 1990s," Brookings Papers on Economic Activity, 1999(1), 1-87.

Lewis, G. (1963): Unionism and Relative Wages in the United States: An Empirical Inquiry. University of Chicago Press.

List, J., D. Millimet, P. Fredriksson, And W. McHone (2003): "Effects of environmental regulations on manufacturing plant births: evidence from a propensity score matching estimator," Review of Economics and Statistics, 85(4), 944-952.

Marshall, A. (1920): Principles of economics: an introductory volume. Macmillan London.

MCCarthy, J. (1999): "Highway fund sanctions and conformity under the Clean Air Act," CRS Report \#RL30131.

McKinney, K. L., And L. Vilhuber (2008): "LEHD Infrastructure files in the Census RDC - Overview," LEHD Working Paper, Revision : 219.

Menezes-Filho, N. A., ANd M.-A. Muendler (2007): Labor reallocation in response to trade reform, vol. 1936. CESifo Working Paper.

Mincer, J. (1974): Schooling, experience, and earnings. National Bureau of Economic Research: distributed by Columbia University Press.

Moretti, E. (2011): "Local Labor Markets," Handbook of Labor Economics, 4, 1237-1313. 
Murphy, K., And R. Topel (1987): "The Evolution of Unemployment in the United States: 1968-1985," NBER Macroeconomics Annual, 2(1), 11-58.

NEAL, D. (1995): "Industry-specific human capital: Evidence from displaced workers," Journal of labor Economics, pp. 653-677.

Notowidigdo, M. (2011): "The Incidence of Local Labor Demand Shocks," NBER Working Paper, w17167.

Ottaviano, G., and G. Peri (2006): "Rethinking the effects of immigration on wages," .

Podgursky, M., and P. Swaim (1987): "Job displacement and earnings loss: Evidence from the Displaced Worker Survey," Industrial and Labor Relations Review, 41(1), 17-29.

RAmey, V., AND M. Shapiro (2001): "Displaced capital: A study of aerospace plant closings," Journal of Political Economy, 109(5), 958-992.

Roy, A. (1951): "Some thoughts on the distribution of earnings," Oxford Economic Papers, pp. 135-146.

Rubin, D. B. (1987): Multiple imputation for nonresponse in surveys. John Wiley \& Sons Inc.

RYAn, S. (2011): "The costs of environmental regulation in a concentrated industry," Mimeo.

Schmieder, J. (2010): "Labor Costs and the Evolution of New Establishments," mimeo.

Solon, G., R. BArsky, And J. PARker (1994): "Measuring the Cyclicality of Real Wages: How Important is Composition Bias," The Quarterly Journal of Economics, pp. 1-25.

The New Republic (April 7th, 2011): "Smoke Signals," The New Republic.

The New York Times (Sep 4th, 2011): "A Debate Arises on Job Creation and Environment," The New York Times.

Topalova, P. (2010): "Factor immobility and regional impacts of trade liberalization: Evidence on poverty from India," American Economic Journal: Applied Economics, 2(4), 1-41.

Topel, R. (1991): "Specific Capital, Mobility, and Wages: Wages Rise with Job Seniority," Journal of Political Economy, 99(1).

Topel, R. H. (1986): "Local Labor Markets," The Journal of Political Economy, 94(S3).

von Wachter, T., J. Song, And J. Manchester (2009): "Long-Term Earnings Losses due to Job Separation During the 1982 Recession: An Analysis Using Longitudinal Administrative Data from 1974 to 2004," Columbia University Department of Economics Discussion Paper Series, pp. 0708-16.

Walker, R. (2011): "Environmental Regulation and Labor Reallocation," American Economic Review: Papers and Proceedings, 101(2).

Wall Street Journal (July 26, 2011): "The Latest Job Killer from the EPA," . 
Figure 1: Nonattainment Counties Across All Pollutants in 1991

(a) Nonattainment for Any Pollutant 1991

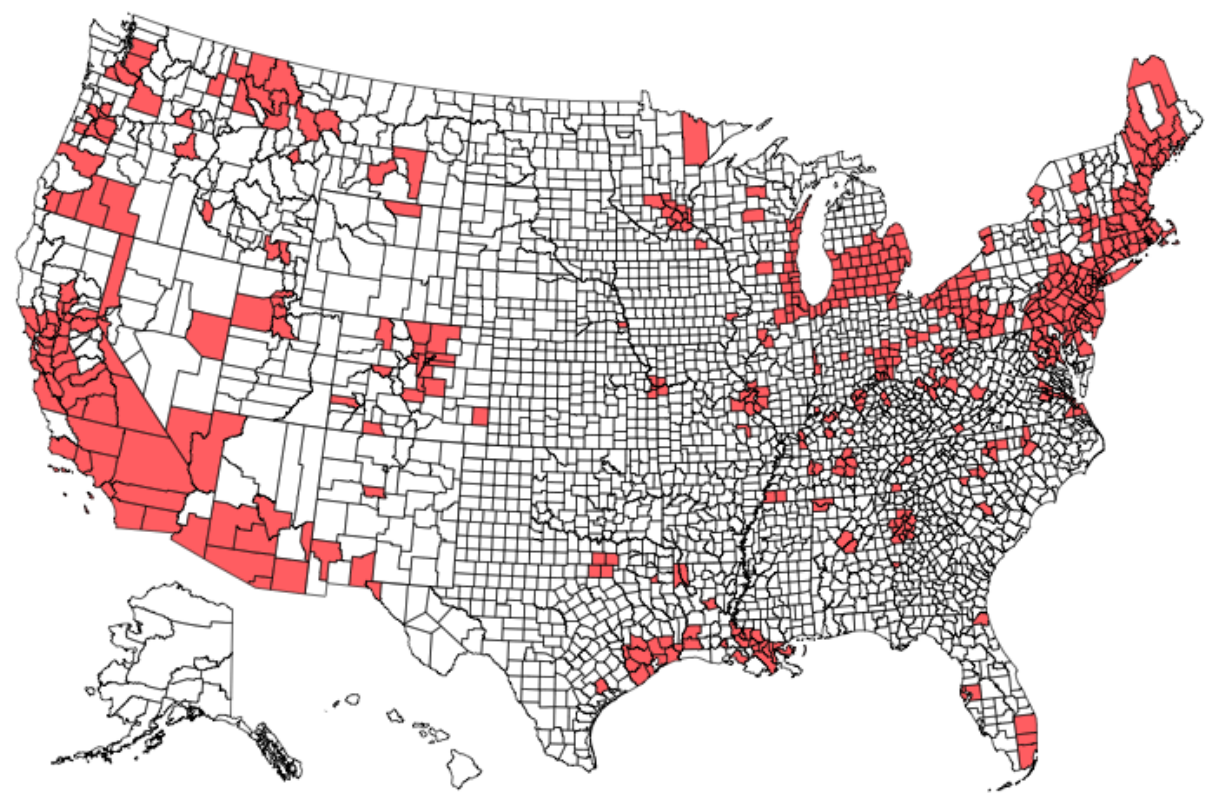

(b) New Nonattainment Counties 1991

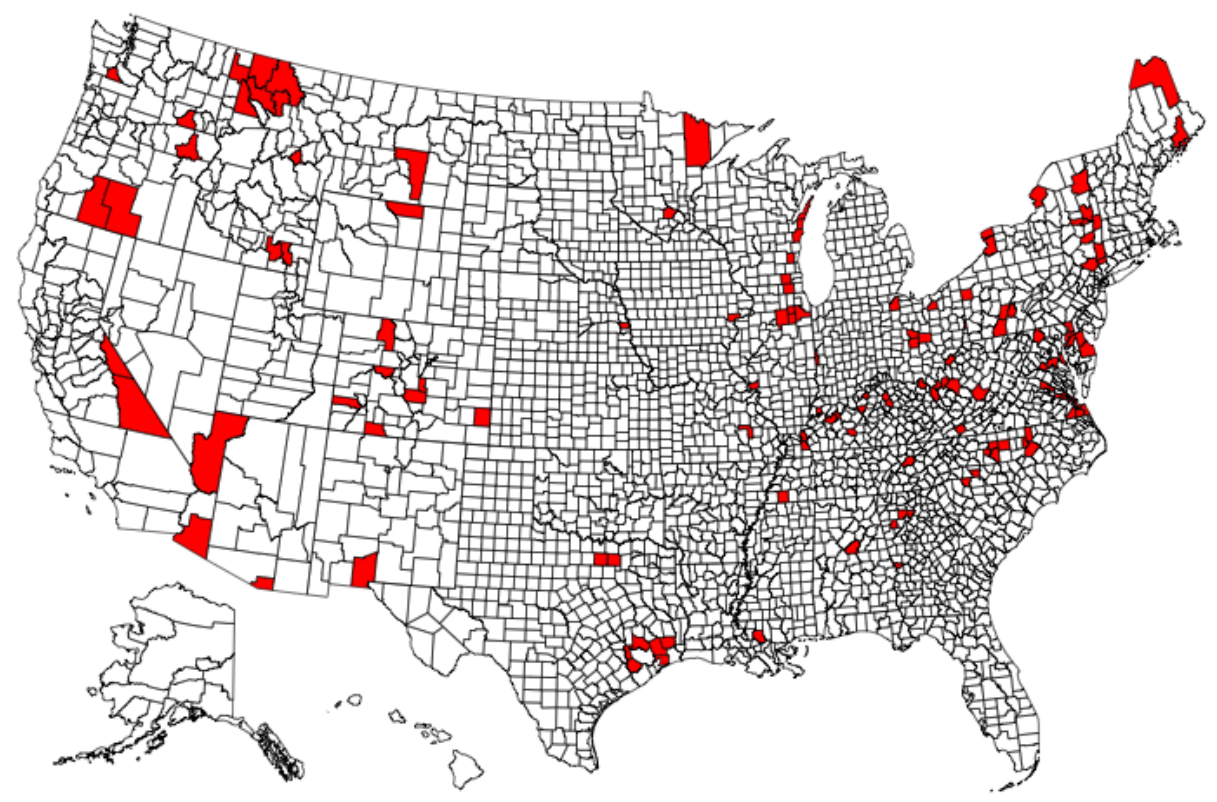

Note: The top panel shows all counties in nonattainment for any pollutant in 1991. The bottom panel shows those counties that switched into nonattainment in 1991 (i.e. from zero nonattainment designations to one or more designations). The top panel shows that while there is considerable amount of variation in the cross-section, nonattainment designation is primarily concentrated in large metropolitan areas and likely to be correlated with other unobservable features of urban labor markets. The bottom panel shows only those counties that switched into nonattainment status in 1991, the first year that the 1990 CAAA were adopted, showing a considerable number of counties that were newly regulated with the passage of the 1990 CAAA. These counties serve as the primary source of identification in the paper. 
Table 1: Sample Statistics: Pre Regulation (1990)

\begin{tabular}{|c|c|c|c|c|c|c|}
\hline & \multicolumn{2}{|c|}{ Attainment } & \multicolumn{2}{|c|}{ Nonattainment } & \multicolumn{2}{|c|}{$\begin{array}{c}\text { Switch Into } \\
\text { Nonattainment }\end{array}$} \\
\hline & $\begin{array}{c}\text { Non } \\
\text { Polluting } \\
\quad(1)\end{array}$ & $\begin{array}{l}\text { Polluting } \\
\text { (2) }\end{array}$ & $\begin{array}{c}\text { Non } \\
\text { Polluting } \\
(3)\end{array}$ & $\begin{array}{c}\text { Polluting } \\
\text { (4) }\end{array}$ & $\begin{array}{c}\text { Non } \\
\text { Polluting } \\
\quad(5)\end{array}$ & $\begin{array}{l}\text { Polluting } \\
\quad(6)\end{array}$ \\
\hline & \multicolumn{6}{|c|}{ Panel A: Plant Characteristics (LBD) } \\
\hline No. of Plants & 6806 & 1707 & 5910 & 1549 & 7622 & 1452 \\
\hline Plant Employment & 146.82 & 244.6 & 133.15 & 266.42 & 144.24 & 234.58 \\
\hline \multirow[t]{2}{*}{ Plant Age } & 8.64 & 10.07 & 8.4 & 10.89 & 8.84 & 10.71 \\
\hline & \multicolumn{6}{|c|}{ Panel B: Workforce Characteristics (LEHD) } \\
\hline Age & 36.88 & 38.61 & 36.67 & 38.3 & 37.04 & 38.1 \\
\hline Education & 13.34 & 13.56 & 13.72 & 14.08 & 13.67 & 13.89 \\
\hline Earnings & 26996.56 & 36950.09 & 31159.89 & 38030.07 & 31692.56 & 39307.95 \\
\hline Separation Rate & 0.22 & 0.08 & 0.24 & 0.11 & 0.23 & 0.08 \\
\hline Same Ind, Same County & 0.04 & 0.01 & 0.05 & 0.02 & 0.04 & 0.01 \\
\hline Same Ind, Diff County & 0.02 & 0.01 & 0.05 & 0.02 & 0.01 & 0.00 \\
\hline Diff Ind, Same County & 0.06 & 0.02 & 0.05 & 0.02 & 0.1 & 0.03 \\
\hline Diff Ind, Diff County & 0.09 & 0.03 & 0.08 & 0.03 & 0.06 & 0.02 \\
\hline Leave Sample & 0.01 & 0.01 & 0.02 & 0.02 & 0.02 & 0.02 \\
\hline \multirow[t]{2}{*}{ Sep: Job to Job } & 0.19 & 0.06 & 0.2 & 0.08 & 0.18 & 0.05 \\
\hline & \multicolumn{6}{|c|}{ Panel C: Sectoral Characteristics (LBD and LEHD) } \\
\hline Total Employment & 233994 & 210386 & 179590 & 146123 & 379553 & 209364 \\
\hline $\begin{array}{l}\text { Total Earnings } \\
\text { (in millions) }\end{array}$ & 6317.03 & 7773.78 & 5596 & 5557.07 & 12029.01 & 8229.67 \\
\hline
\end{tabular}

NOTES: Sample statistics for the "base" states from which the LEHD workforce sample is drawn (IL, MD, WA, WI). Since these are statistics for the "base" year, they only include the manufacturing industry. All dollar amounts are reported in 1990 dollars. Separation is defined as working in 1990 and working either at a different plant in 1991 or having missing earnings in 1991. The separation rate is further decomposed into five different categories listed in the table. LBD denotes characteristics derived from the LBD sample. LEHD denotes characteristics from the LEHD worker cohort sample. Source LEHD, LBD. 
Figure 2: Fraction of Permitted Plants By Industry in Nonattainment Counties

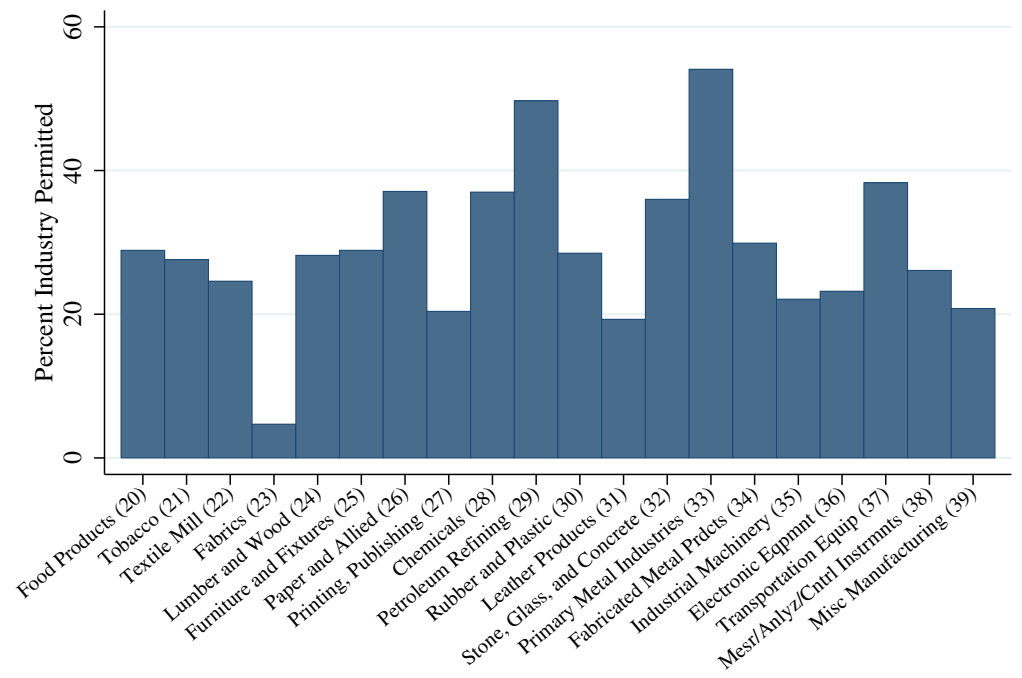

Note: This figure shows the fraction of plants by major industry in nonattainment counties that have air pollution operating permits as mandated by the CAA. The percentages are weighted by employment. This figure shows that within a specific 2-digit industry SIC code, less than half of most industries are classified as polluters (and hence regulated under nonattainment). Source LBD 1985-2005. 
Figure 3: Sector Level Employment Before and After 1990 CAAA

(a) Employment Trends Before/After 1990 CAAA

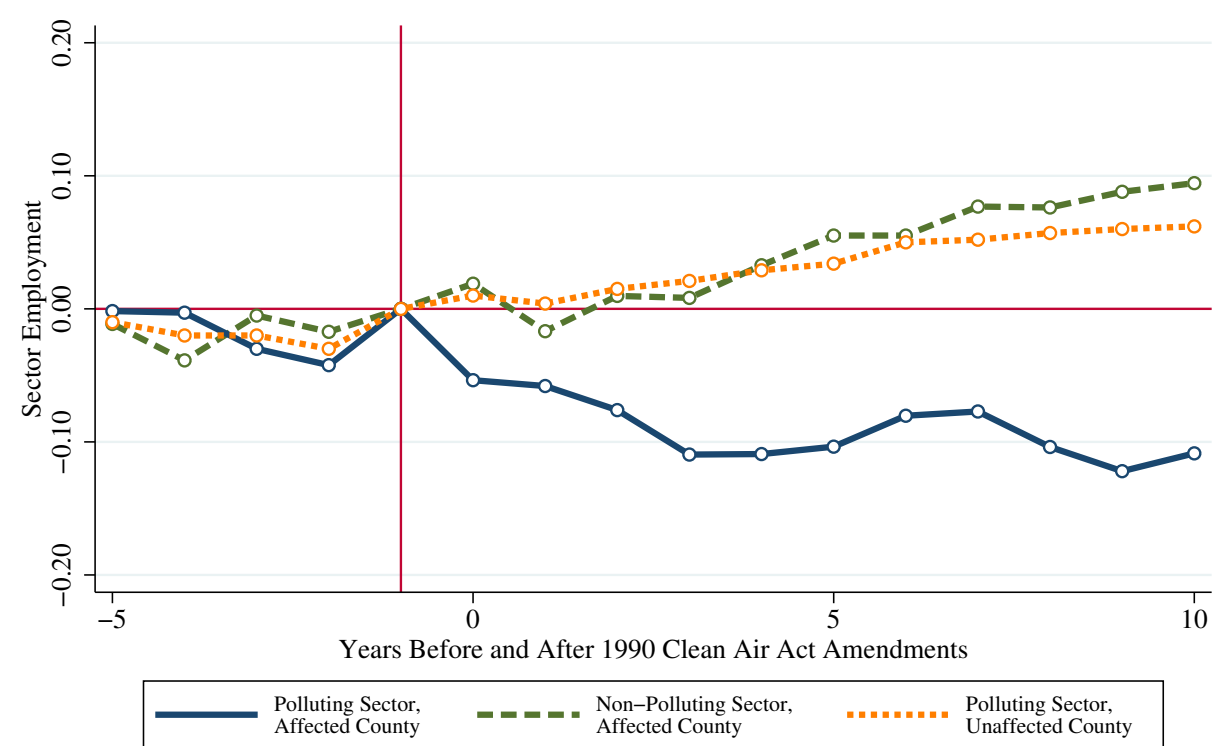

(b) Differences in Employment Trends Before/After 1990 CAAA

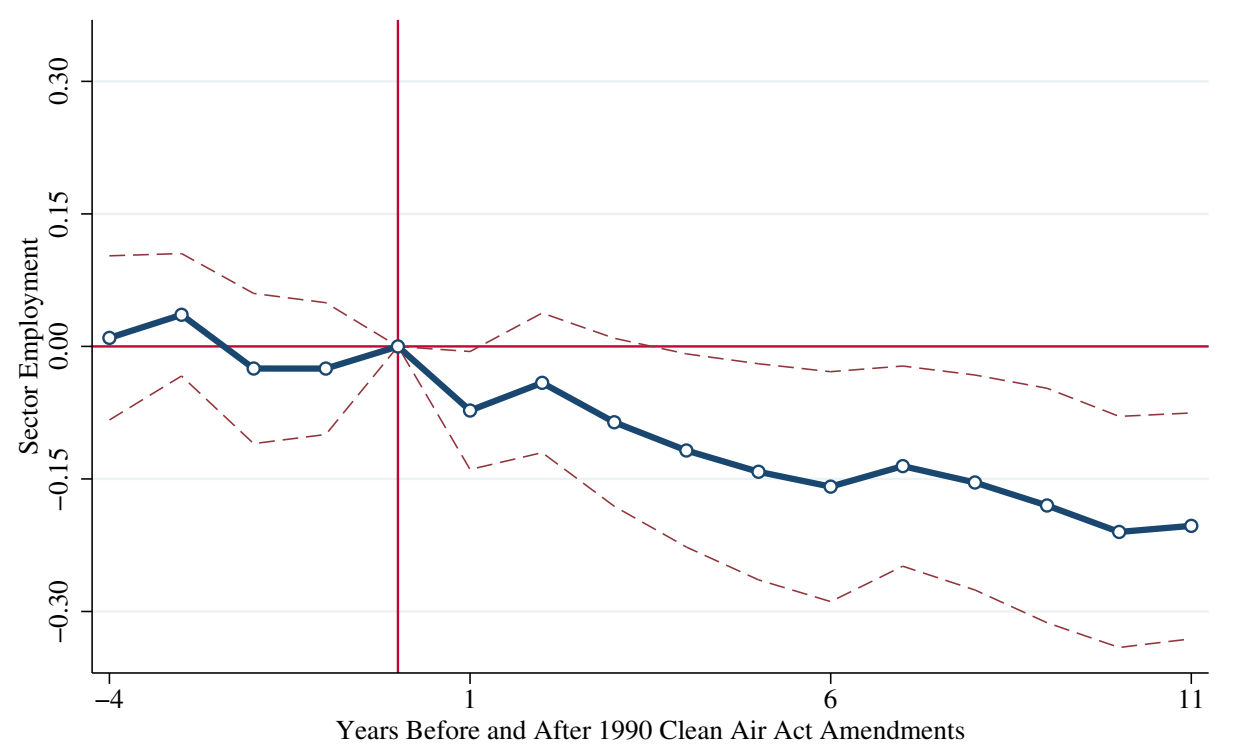

Note: Plotted are the coefficient estimates from a version of equation (5). Specifically, Panel (a) plots event time indicators for various sectors of the manufacturing industry, which correspond to the "second-order" interaction terms from the triple-difference estimator in equation (5). Affected counties correspond to those counties that switched into EPA's nonattainment designation in 1991. The solid line represents employment in the newly-regulated, polluting sector, and the dashed lines represents employment in other sectors (normalized to zero in year $\tau=-1$ ). Panel (b) plots the difference in event time indicators from Panel (a), corresponding to the "triple-difference" regression coefficients in equation (5). The first year of the nonattainment designation corresponds to year 1 in the graph. The dashed lines represent 95\% confidence intervals. An auxiliary test of the slopes in Figure 3b, before and after regulation, rejects the null of equal slope with a $p$-value of 0.03 . See text for details. Source: LBD. 
Table 2: Effect of Sector Level Regulation on Earnings

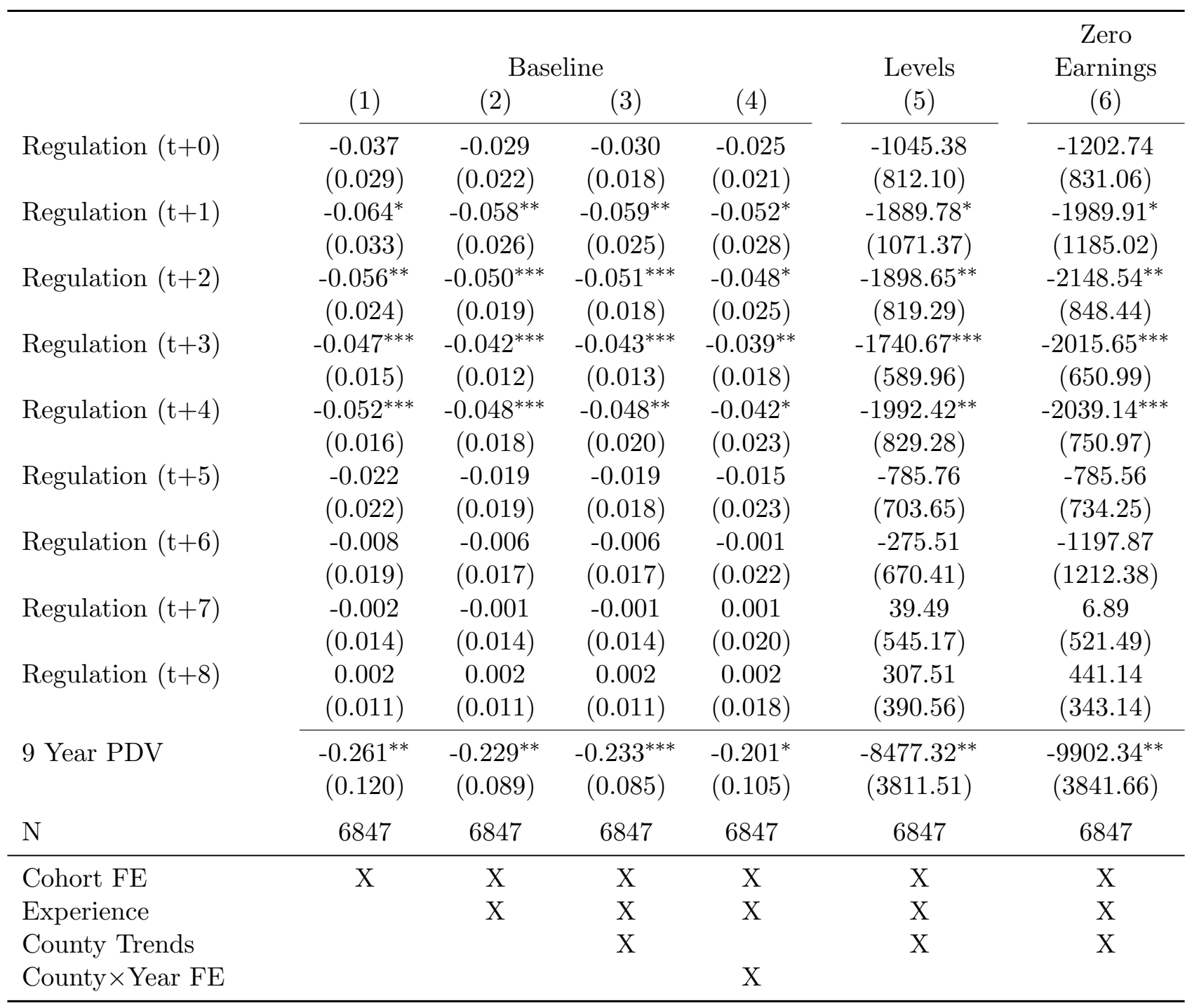

Note: This table reports regression coefficients from equation (6). Each column corresponds to a different regression, where the results are presented for three different samples as indicated in the table headings. An observation is a cohort $\times$ year so that each cohort county has two observations per year. Standard errors are in parentheses and are calculated allowing for an arbitrary variancecovariance matrix within each county. The baseline sample is estimated using three different log specifications (columns (1)-(4)), and exponentiated coefficients are reported using the translation $\left(\exp \left(\eta_{1}^{k}\right)-1\right)$. The regressions are weighted by the 1990 cohort size. The final row of the table reports the discounted sum of the coefficients using a 4 percent annual discount rate (with discount factor $\beta$ ). Columns (1)-(4) use the translation $\sum_{k=0}^{8} \beta^{k}\left(\exp \left(\eta_{1}^{k}\right)-1\right)$. Standard errors for the final row are calculated using the delta method. Earnings are reported in 1990(\$). See text for details. Source: LEHD.

$* * *, * *, *$ denotes statistical significance at the 1,5 , and 10 percent levels, respectively. 
Figure 4: Cohort Wage Trends After Nonattainment Designation

(a) Cohort Wage Trends After Nonattainment Designation

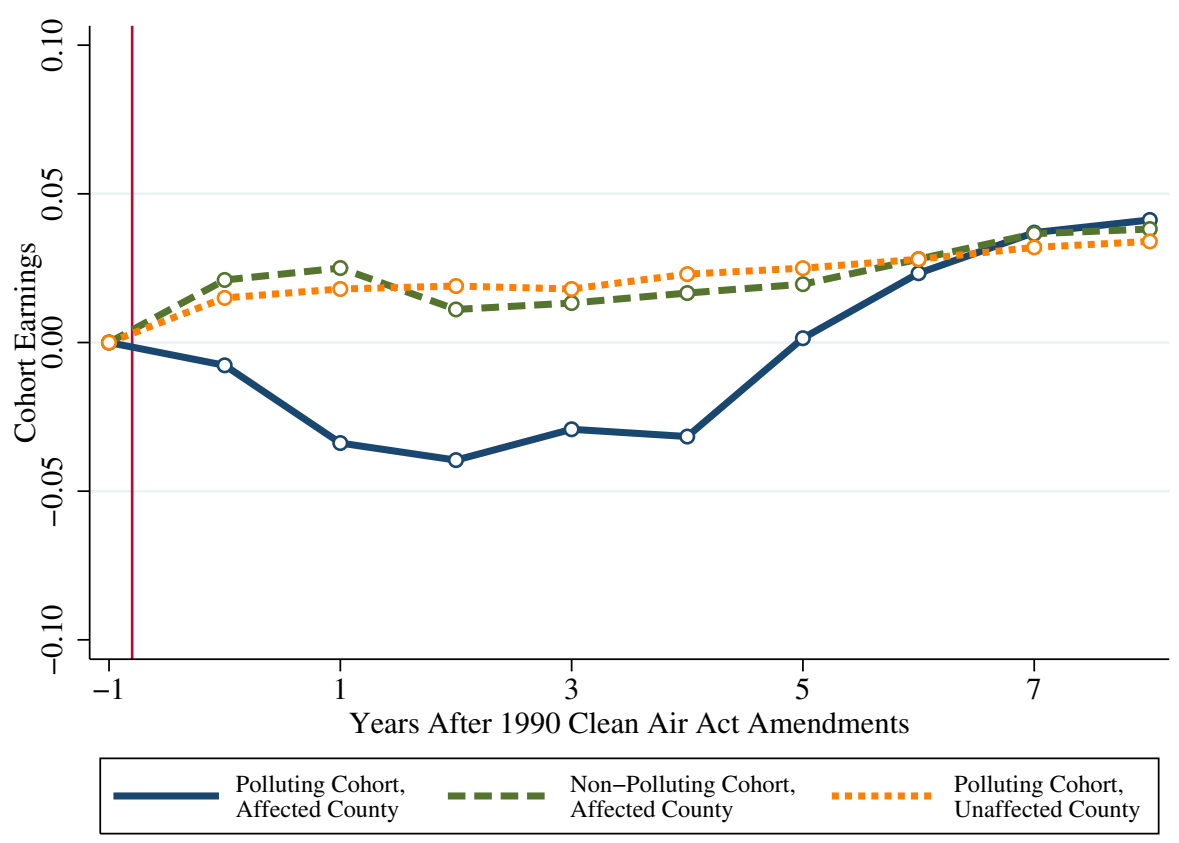

(b) Differences in Cohort Wage Trends After Nonattainment Designation

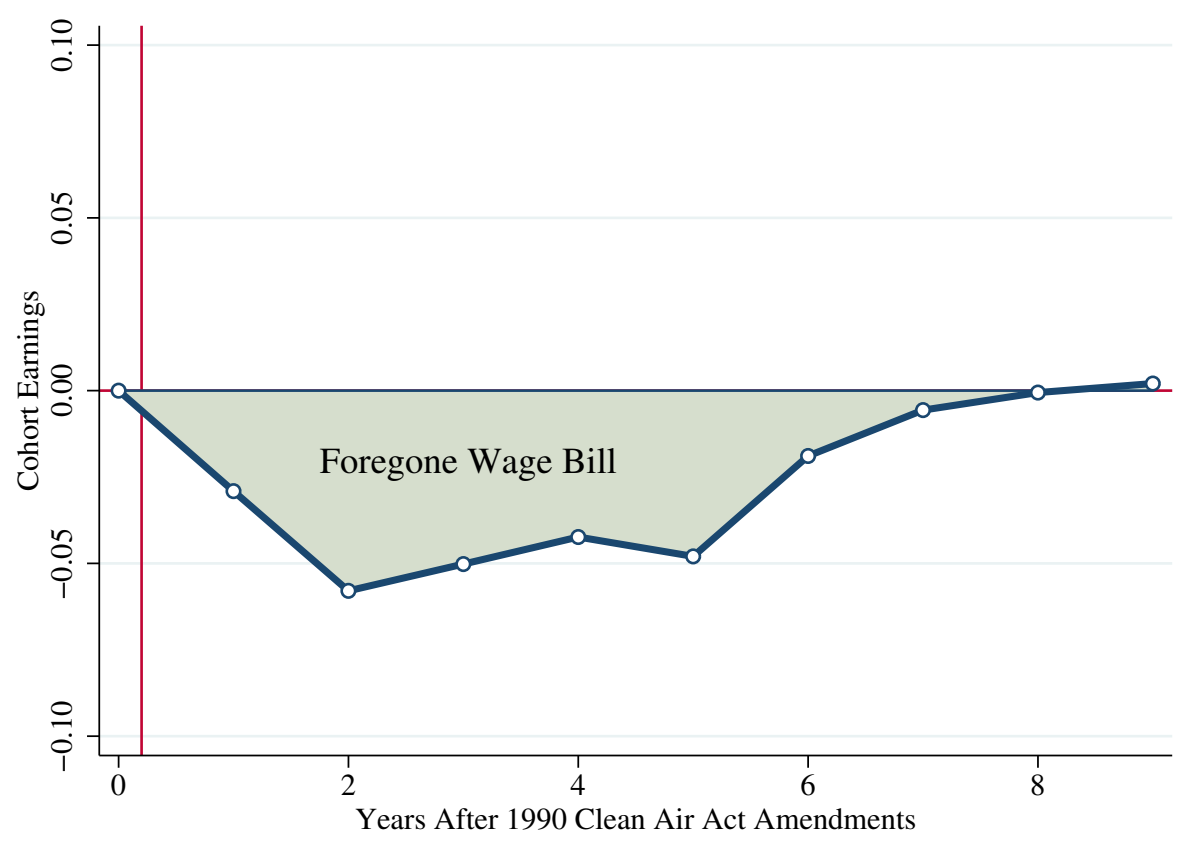

Note: Plotted are the coefficient estimates from a version of equation (6). Specifically, Panel (a) plots the event time indicators for three sets of cohorts, which correspond to the "second-order" interaction terms from the triple-difference estimator in equation (6). Affected counties correspond to the set of counties that switched into EPA's nonattainment designation in 1991. Cohorts are defined by place of work in 1990. The solid line represents the cohort that worked in the newly-regulated, polluting sector in 1990, and the dashed lines represents the cohorts that did not work in the newly-regulated sectors in 1990. Panel (b) plots the "triple-difference" regression coefficients in equation (6), corresponding to the difference in the dashed and solid lines in Panel (a). See text for details. Source: LEHD. 
Table 3: Testing for "Local" General Equilibrium Effects: County Level Earnings Estimates

\begin{tabular}{|c|c|c|c|c|c|}
\hline & (1) & $\begin{array}{c}\text { Baseline } \\
\quad(2)\end{array}$ & (3) & $\begin{array}{l}\text { Levels } \\
(4)\end{array}$ & $\begin{array}{c}\text { Zero } \\
\text { Earnings } \\
\quad(5)\end{array}$ \\
\hline 9 Year PDV & $\begin{array}{c}-0.110^{* * *} \\
(0.034)\end{array}$ & $\begin{array}{c}-0.091^{* * *} \\
(0.038)\end{array}$ & $\begin{array}{c}-0.090^{* * *} \\
(0.042)\end{array}$ & $\begin{array}{c}-3597.67^{* * *} \\
(1342.59)\end{array}$ & $\begin{array}{c}-3837.45^{* * *} \\
(1670.12)\end{array}$ \\
\hline $\mathrm{N}$ & 3823 & 3823 & 3823 & 3823 & 3823 \\
\hline Cohort FE & $\mathrm{X}$ & $\mathrm{X}$ & $\mathrm{X}$ & $\mathrm{X}$ & $\mathrm{X}$ \\
\hline Experience & & $\mathrm{X}$ & $\mathrm{X}$ & $\mathrm{X}$ & $\mathrm{X}$ \\
\hline County Trends & & & $\mathrm{X}$ & $\mathrm{X}$ & $\mathrm{X}$ \\
\hline
\end{tabular}

Note: This table reports regression coefficients from a version of equation (3). Each column corresponds to a different regression, where the results are presented for three different samples as indicated in the table headings. An observation is a cohort $\times$ year so that each cohort county has two observations per year. Standard errors are in parentheses and are calculated allowing for an arbitrary variance-covariance matrix within each county. The baseline sample is estimated using three different log specifications (columns (1)$(3))$, and exponentiated coefficients are reported using the translation $\left(\exp \left(\eta_{1}^{k}\right)-1\right)$. The regressions are weighted by the 1990 cohort size. The final row of the table reports the discounted sum of the coefficients using a 4 percent annual discount rate (with discount factor $\beta$ ). Columns (1)-(3) use the translation $\sum_{k=0}^{8} \beta^{k}\left(\exp \left(\eta_{1}^{k}\right)-1\right)$. Standard errors for the final row are calculated using the delta method. Earnings are reported in 1990(\$). See text for details. Source: LEHD.

***,**** denotes statistical significance at the 1,5 , and 10 percent levels, respectively.

Figure 5: Job Transition Rates from the Newly Regulated Sector

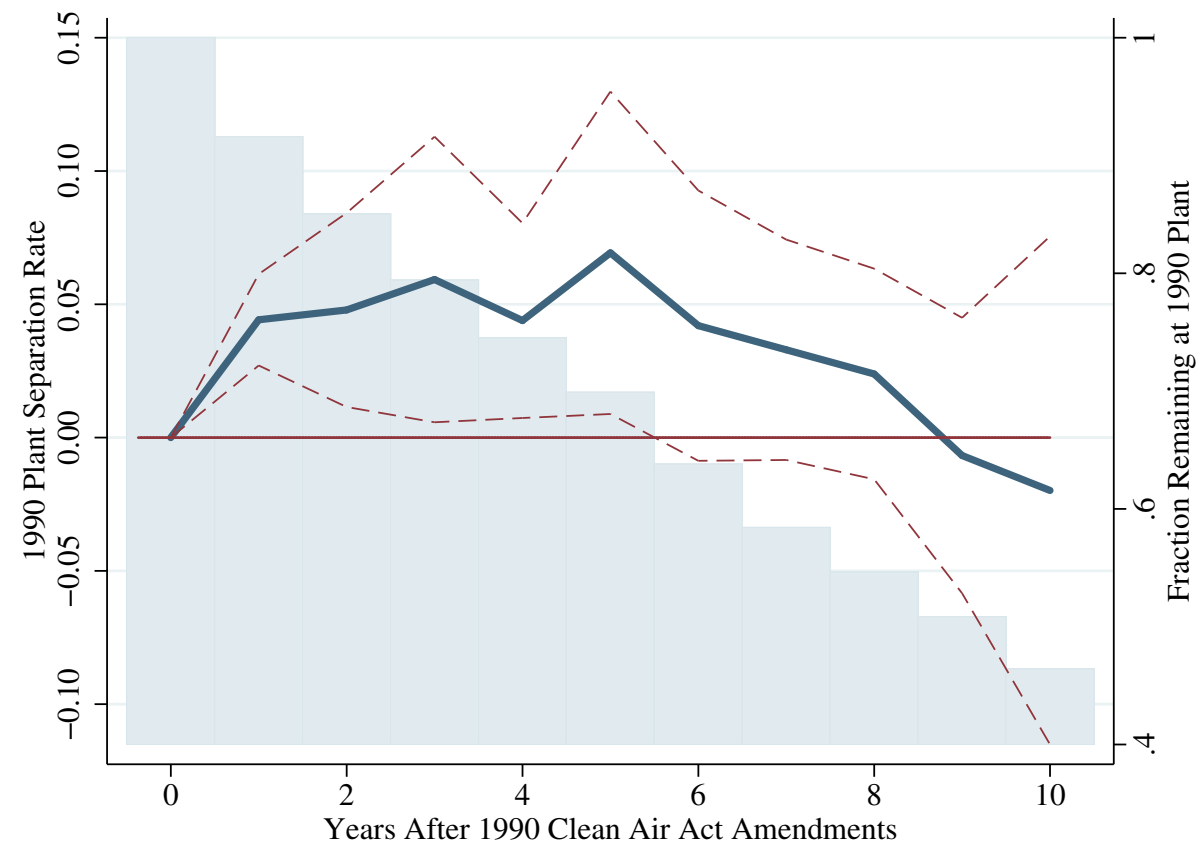

Note: Plotted are the coefficient estimates from a version of equation (6), which pertain to the difference in separation probabilities for the newly regulated sector after the change in regulations. See text for details. The dashed lines represent $95 \%$ confidence intervals. The bars represent the survivor probability for workers in polluting plants of newly designated nonattainment counties. Source: LEHD. 
Table 4: Effect of Sector Level Regulation on Earnings: Decomposition Based on Sectoral Transitions

\begin{tabular}{|c|c|c|c|c|c|c|}
\hline & $\begin{array}{l}\text { Stayer } \\
(1)\end{array}$ & $\begin{array}{c}\text { Separator } \\
(2)\end{array}$ & $\begin{array}{c}\text { Separator: } \\
\text { Same Industry } \\
\text { Same County } \\
(3)\end{array}$ & $\begin{array}{c}\text { Separator: } \\
\text { Diff. Industry } \\
\text { Same County } \\
(4)\end{array}$ & $\begin{array}{c}\text { Separator } \\
\text { Same Industry } \\
\text { Diff. County } \\
(5)\end{array}$ & $\begin{array}{c}\text { Separator } \\
\text { Diff. Industry } \\
\text { Diff. County } \\
(6)\end{array}$ \\
\hline Regulation $(t+0)$ & $\begin{array}{c}0.007 \\
(0.022)\end{array}$ & $\begin{array}{c}-0.125^{* * *} \\
(0.038)\end{array}$ & $\begin{array}{c}-0.056^{* *} \\
(0.026)\end{array}$ & $\begin{array}{c}-0.162^{* * *} \\
(0.040)\end{array}$ & $\begin{array}{c}-0.177^{* * *} \\
(0.037)\end{array}$ & $\begin{array}{c}-0.168^{* * *} \\
(0.033)\end{array}$ \\
\hline Regulation $(\mathrm{t}+1)$ & $\begin{array}{c}-0.016 \\
(0.028)\end{array}$ & $\begin{array}{c}-0.218^{* * *} \\
(0.028)\end{array}$ & $\begin{array}{c}-0.151^{* * *} \\
(0.032)\end{array}$ & $\begin{array}{c}-0.235^{* * *} \\
(0.024)\end{array}$ & $\begin{array}{c}-0.196^{* * *} \\
(0.050)\end{array}$ & $\begin{array}{c}-0.245^{* * *} \\
(0.022)\end{array}$ \\
\hline Regulation $(t+2)$ & $\begin{array}{c}0.002 \\
(0.022)\end{array}$ & $\begin{array}{c}-0.308^{* * *} \\
(0.016)\end{array}$ & $\begin{array}{c}-0.189^{* * *} \\
(0.030)\end{array}$ & $\begin{array}{c}-0.298^{* * *} \\
(0.018)\end{array}$ & $\begin{array}{c}-0.241^{* * *} \\
(0.026)\end{array}$ & $\begin{array}{c}-0.313^{* * *} \\
(0.013)\end{array}$ \\
\hline Regulation $(\mathrm{t}+3)$ & $\begin{array}{l}-0.006 \\
(0.015)\end{array}$ & $\begin{array}{c}-0.313^{* * *} \\
(0.040)\end{array}$ & $\begin{array}{c}-0.206^{* * *} \\
(0.055)\end{array}$ & $\begin{array}{c}-0.309^{* * *} \\
(0.044)\end{array}$ & $\begin{array}{c}-0.224^{* * *} \\
(0.020)\end{array}$ & $\begin{array}{c}-0.321^{* * *} \\
(0.029)\end{array}$ \\
\hline Regulation $(\mathrm{t}+4)$ & $\begin{array}{l}-0.019 \\
(0.021)\end{array}$ & $\begin{array}{c}-0.244^{* * *} \\
(0.038)\end{array}$ & $\begin{array}{c}-0.143^{* * *} \\
(0.041)\end{array}$ & $\begin{array}{c}-0.230^{* * *} \\
(0.046)\end{array}$ & $\begin{array}{c}-0.153^{* * *} \\
(0.021)\end{array}$ & $\begin{array}{c}-0.249^{* * *} \\
(0.024)\end{array}$ \\
\hline Regulation $(\mathrm{t}+5)$ & $\begin{array}{c}0.010 \\
(0.020)\end{array}$ & $\begin{array}{c}-0.194^{* * *} \\
(0.024)\end{array}$ & $\begin{array}{c}-0.117^{* * *} \\
(0.043)\end{array}$ & $\begin{array}{c}-0.185^{* * *} \\
(0.028)\end{array}$ & $\begin{array}{c}-0.140^{* * *} \\
(0.021)\end{array}$ & $\begin{array}{c}-0.188^{* * *} \\
(0.014)\end{array}$ \\
\hline Regulation $(\mathrm{t}+6)$ & $\begin{array}{c}0.015 \\
(0.014)\end{array}$ & $\begin{array}{c}-0.118^{* * *} \\
(0.011)\end{array}$ & $\begin{array}{c}-0.011 \\
(0.026)\end{array}$ & $\begin{array}{c}-0.097^{* * *} \\
(0.017)\end{array}$ & $\begin{array}{l}-0.056 \\
(0.035)\end{array}$ & $\begin{array}{c}-0.116^{* * *} \\
(0.013)\end{array}$ \\
\hline Regulation $(t+7)$ & $\begin{array}{c}0.007 \\
(0.014)\end{array}$ & $\begin{array}{c}-0.050^{* * *} \\
(0.014)\end{array}$ & $\begin{array}{c}0.010 \\
(0.027)\end{array}$ & $\begin{array}{c}-0.043^{* *} \\
(0.018)\end{array}$ & $\begin{array}{l}-0.008 \\
(0.031)\end{array}$ & $\begin{array}{l}-0.017 \\
(0.017)\end{array}$ \\
\hline Regulation $(t+8)$ & $\begin{array}{c}0.006 \\
(0.021)\end{array}$ & $\begin{array}{c}-0.012 \\
(0.016)\end{array}$ & $\begin{array}{c}0.010 \\
(0.026)\end{array}$ & $\begin{array}{c}0.013 \\
(0.031)\end{array}$ & $\begin{array}{l}-0.003 \\
(0.027)\end{array}$ & $\begin{array}{c}0.008 \\
(0.014)\end{array}$ \\
\hline 9-Year PDV & $\begin{array}{c}0.008 \\
(0.083)\end{array}$ & $\begin{array}{c}-1.375^{* * *} \\
(0.063)\end{array}$ & $\begin{array}{c}-0.740^{* * *} \\
(0.125)\end{array}$ & $\begin{array}{c}-1.349^{* * *} \\
(0.073)\end{array}$ & $\begin{array}{c}-1.025^{* * *} \\
(0.158)\end{array}$ & $\begin{array}{c}-1.389^{* * *} \\
(0.060)\end{array}$ \\
\hline $\mathrm{N}$ & 6847 & 6847 & 6847 & 6847 & 6847 & 6847 \\
\hline Cohort FE & $\mathrm{X}$ & $\mathrm{X}$ & $\mathrm{X}$ & $\mathrm{X}$ & $\mathrm{X}$ & $\mathrm{X}$ \\
\hline Experience & $\mathrm{X}$ & $\mathrm{X}$ & $\mathrm{X}$ & $\mathrm{X}$ & $\mathrm{X}$ & $\mathrm{X}$ \\
\hline
\end{tabular}

Note: This table reports regression coefficients from equation (6). Each column corresponds to a different regression, where the results are presented for six different samples as indicated in the table headings. An observation is a cohort $\times$ year so that each cohort county has two observations per year. Standard errors are in parentheses and are calculated allowing for an arbitrary variance-covariance matrix within each county. Exponentiated coefficients are reported using the translation $\left(\exp \left(\eta_{1}^{k}\right)-1\right)$. The regressions are weighted by the 1990 cohort size. The final row of the table reports the discounted sum of the coefficients using a 4 percent annual discount rate (with discount factor $\beta$ ) and the translation $\sum_{k=0}^{8} \beta^{k}\left(\exp \left(\eta_{1}^{k}\right)-1\right)$. Standard errors for the final row are calculated using the delta method. Earnings are reported in 1990(\$). See text for details. Source: LEHD.

***,**,* denotes statistical significance at the 1,5 , and 10 percent levels, respectively. 
Figure 6: Decomposing Differences in Job Transition Rates

(a) Different Industry Different County

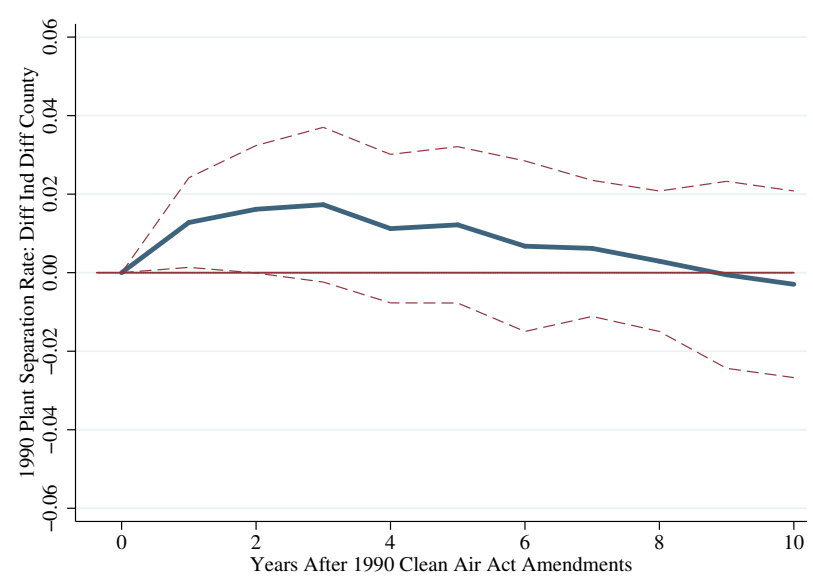

(c) Different Industry Same County

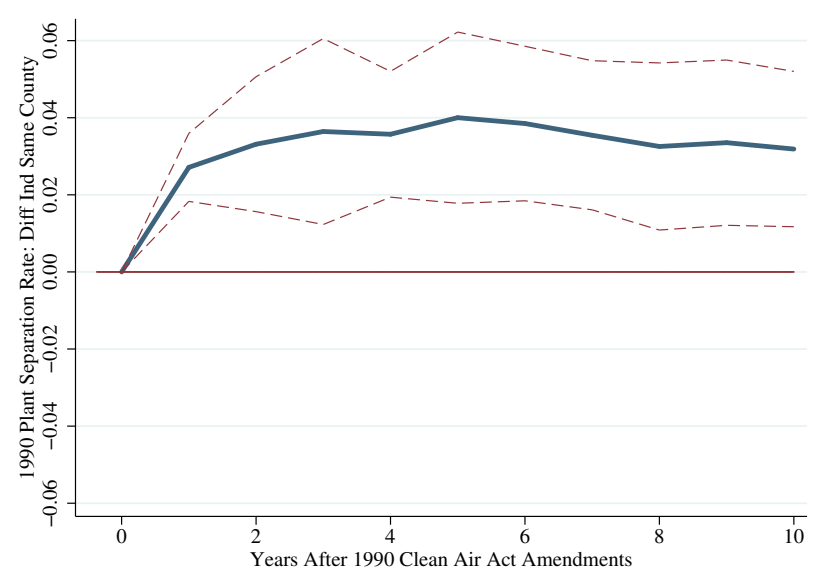

(b) Same Industry Same County

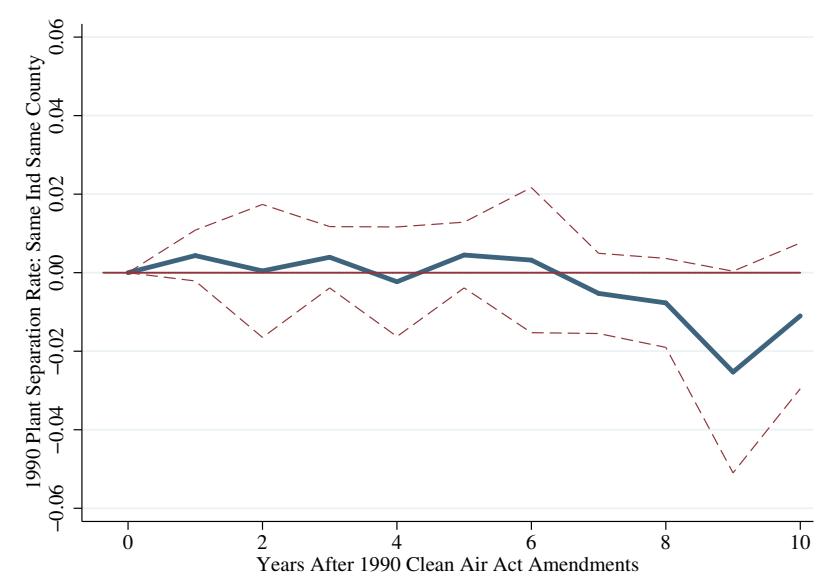

(d) Same Industry Different County

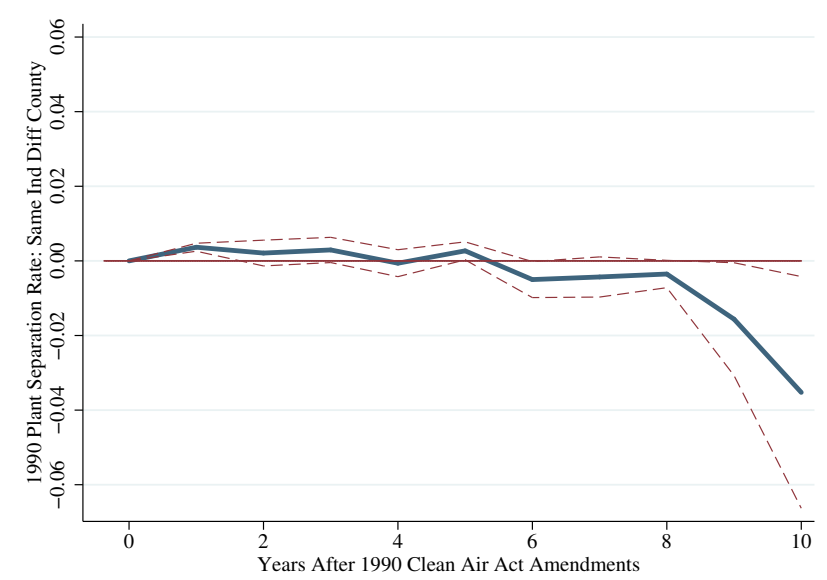

NotE: Plotted are the coefficient estimates that decompose the separation probabilities into destination sectors. The plotted coefficients come from a version of equation (6), which pertain to the difference in transition probabilities for the newly regulated sector after the change in regulations. See text for details. The dashed lines represent $95 \%$ confidence intervals. Source: LEHD. 
Figure 7: Effect of Sector Level Regulation on Earnings: Decomposition Based on Sectoral Transitions

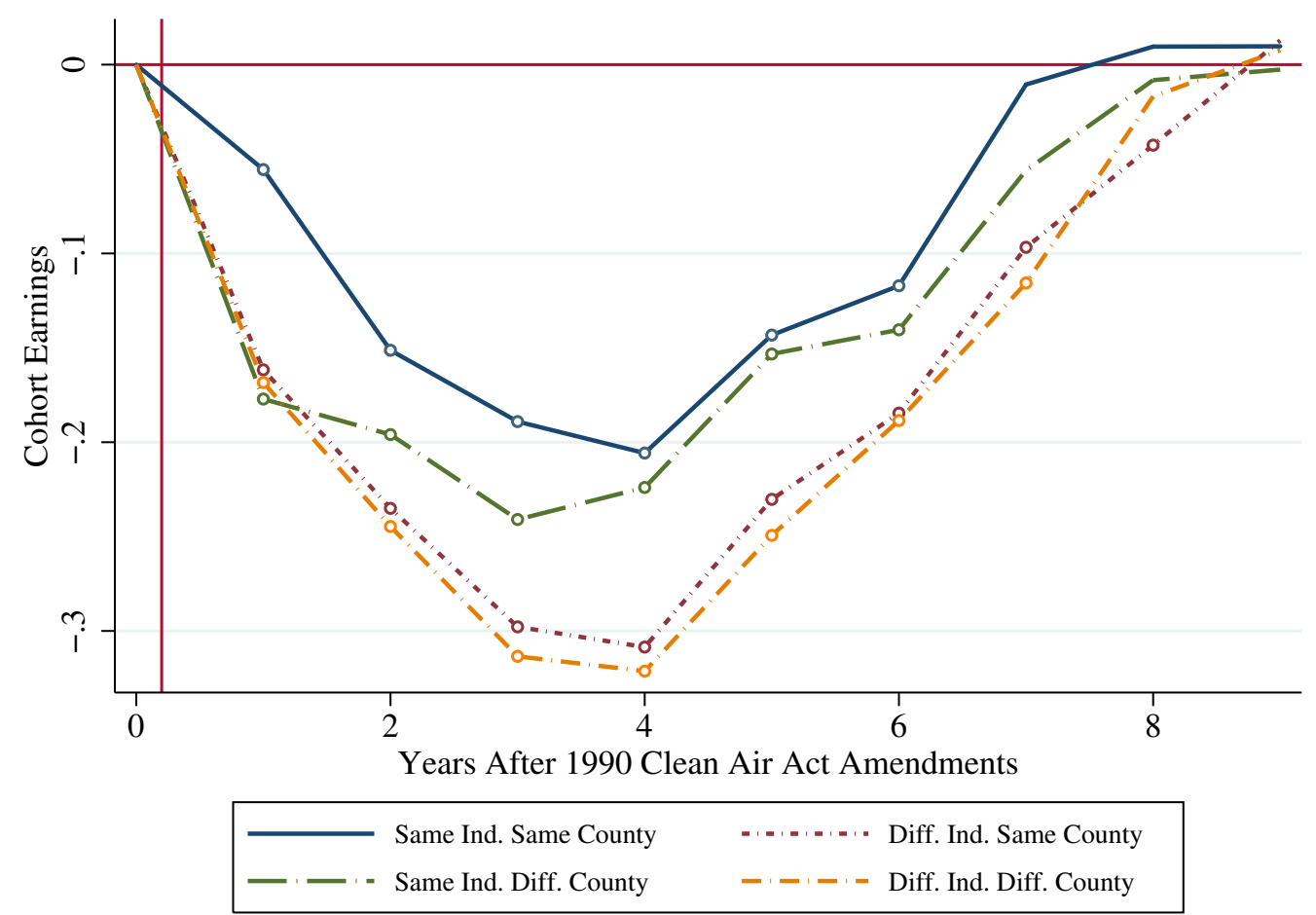

Note: Plotted are the coefficient estimates from a various versions of equation (6) fit for each sub-category of job transitions. The figure shows that worker transitions that result in a new job in the same industry experience a far lower earnings loss than those workers who switch industries. The lines correspond to the estimates reported in columns (3)-(6) of Table 4. See Section 7.6 for details. Source: LEHD. 


\section{A Appendix: Data}

\section{A.1 LEHD Earnings Data Construction}

This section describes the basic data cleaning necessary to arrive at the analysis files used in this project. For a much more detailed description of the LEHD files see McKinney and Vilhuber (2008) and Abowd, Stephens, Vilhuber, Andersson, McKinney, Roemer, and Woodcock (2008). I begin creating the data by creating a "baseyear" file of workers who worked in the manufacturing industry in 1990 in the states for which I have data in 1990 (MD, IL, WA, WI). I then use the Employment History Files (EHF) from all states in all subsequent years to "follow" these workers over time, irrespective of whether or not they remain in their initial state. Using these earnings histories, I assign the worker to their highest paying job in a given year. I exclude any worker whose maximum annual earnings over their entire work history was less than $\$ 10,000$. Using this work history, I assign workers to "cohorts" where a cohort is defined by the county and sector that a worker worked in 1990.

Two important limitations of the LEHD data in the context of this project are the temporal coverage over time (detailed further in Table A.1) and the inability to observe the unit of work with certainty. To be more specific about the latter issue, state UI data records the firm that an employee works at in a given quarter. If a firm has more than one operating unit within the same state, then it becomes difficult to say with certainty which of the units the employee works. Approximately 30 to 40 percent of state-level employment is concentrated in employers that operate more than one establishment in that state. If there is more than a single plant belonging to a firm within a given state, the Census imputes place of work using a non-ignorable missing data model with multiple imputation. The model imputes establishment-of-employment using two key characteristics available in the LEHD Infrastructure Files: 1) distance between place-of-work and place-of-residence and 2) the distribution of employment across establishments of multiunit employers. This same imputation file is used in the creation of Census's Quarterly Workforce Indicators. See McKinney and Vilhuber (2008) for more information.

This place of work distinction is important for my research design as CAA regulations only affect polluting plants in nonattainment counties. If a firm has a plant in a nonattainment county and another plant within an attainment county of the same state, then the only workers who should be affected are those in the nonattainment plant. Thus, I need the plant level imputation to distinguish between those workers who are affected and those who are not. In practice, around 60 percent of the workforce in my sample resides in a single-unit firm, and thus the remaining 40 percent of workers have to be matched using imputation. ${ }^{53}$ The imputation procedure yields 10 (not mutually exclusive) implicates pertaining to a person's place of work. This requires the creation of 10 separate datasets pertaining to the 10 implicates, estimating the model on each of these datasets, and combining the parameter estimates as in Rubin (1987). ${ }^{54}$

\section{A.2 Longitudinal Business Database (LBD)}

The Longitudinal Business Database (LBD) is a longitudinal plant level database that covers the universe of establishments in the United States from 1975-2005. In each year, there consists of detailed industry information as well as information on employment and earnings for the particular plant. Also included in the data are years of entry and exit for the particular plant (and hence firm age). In the analysis, I limit the dataset to include only establishments within the manufacturing and utility sectors. I also exclude any establishments for which the maximum employment over the sample frame is less than 50 employees as well as any establishment with a lifespan of less than 3 years. Since EPA regulations primarily apply to major sources with potential to emit of more than 100 tons per year, excluding these smaller establishments has little effect on the estimates. Lastly, there is an issue with the LBD data for multi-unit establishments in 1988 (Jarmin and Miranda 2002). I have dropped the employment and earnings data for each multi-unit establishment in 1988 and imputed the missing data using the midpoint of 1987 and 1989 employment and payroll measures (conditional on firm survival).

\footnotetext{
${ }^{53}$ I have also estimated the models in this paper using only workers from "single-unit" plants, and the results (not reported) are similar to those presented here.

${ }^{54}$ Multiple imputation is used in other popular datasets such as the National Health and Nutrition Examination Survey (NHANES).
} 
Table A.1: LEHD State Year Coverage: Based on Years with Unit-to-Work Imputation Data

\begin{tabular}{lccc}
\hline State & State Abbreviation & First Year & Last Year \\
\hline Alabama & AL & 2001 & 2004 \\
Arkansas & AR & 2002 & 2004 \\
California & CA & 1991 & 2003 \\
Colorado & CO & 1993 & 2004 \\
Delaware & DE & 1998 & 2004 \\
Florida & FL & 1992 & 2004 \\
Iowa & IA & 1998 & 2004 \\
Idaho & ID & 1991 & 2004 \\
Illinois & IL & 1990 & 2004 \\
Indiana & IN & 1998 & 2004 \\
Kansas & KS & 1993 & 2004 \\
Kentucky & KY & 2001 & 2004 \\
Maryland & MD & 1990 & 2004 \\
Maine & ME & 1996 & 2004 \\
Minnesota & MN & 1994 & 2004 \\
Missouri & MO & 1995 & 2004 \\
Montana & MT & 1993 & 2004 \\
North Carolina & NC & 1991 & 2003 \\
North Dakota & ND & 1998 & 2004 \\
New Jersey & NJ & 1996 & 2004 \\
New Mexico & NM & 1995 & 2004 \\
Oklahoma & OK & 1999 & 2004 \\
Oregon & OR & 1991 & 2004 \\
Pennsylvania & PA & 1997 & 2004 \\
South Carolina & SC & 1998 & 2004 \\
Texas & TX & 1995 & 2004 \\
Virginia & VA & 1995 & 2004 \\
Vermont & VT & 2000 & 2004 \\
Washington & WA & 1990 & 2004 \\
Wisconsin & WI & 1990 & 2004 \\
West Virginia & WV & 1997 & 2004 \\
\hline
\end{tabular}

\section{A.3 EPA Air Facility Subsystem (AFS)}

The EPA's Air Facility System (AFS) contains compliance and enforcement data and permit data for stationary sources of air pollution regulated by EPA, state and local air pollution agencies. The permit data is the primary data element used in this analysis, detailing whether or not a particular plant has ever had a Title V Operating Permit, a New Source Review Permit, a "Prevention of Significant Deterioration" permit, or a "Pre-Construction" permit issued under the Clean Air Act. These are legally enforceable documents that authorities issue to air pollution sources whether or not they are in a nonattainment region. The permits are issued to all large sources (major sources) and a limited number of smaller sources (called area sources, minor sources, or nonmajor sources). Permits include pollution-control requirements from federal or state regulations that apply to a particular plant. Construction permits specify what construction is allowed, what emission limits must be met, and often how the source must be operated. Thus, for each AFS plant I match to the Census data (see section A.4), I include an indicator for whether or not they have ever been issued one of these permits. This is my plant-level "polluter" indicator detailed in the text.

\section{A.4 Matching Algorithm and Match Results}

To match plant level data from the EPA's Air Facility Subsystem to the Longitudinal Business Database, I rely upon a name and address matching algorithm. Using information from the EPA and the Census on plant name, 
detailed address, and industry, I iterate over various combinations of these observables to construct unique matches between the two datasets. The name and address data from the Census comes from the Standard Statistical Establishment List (SSEL) which can be linked to the Longitudinal Business Database (LBD) and Longitudinal Employer Household Dynamics file (LEHD) after the matching process. Since I have annual plant level information from the Census and the EPA AFS database is only available as a cross-section, I construct a match candidate for each year in the Census data. That is, for every year in the SSEL, I perform a match of the SSEL to the AFS database using information on address, location, industry, and name. I then combine all possible matches across all years and select the modal match from the full distribution of potential matches. Thus, for each SSEL year in the loop, the basic matching algorithm is as follows:

1. Select a matching group of characteristics to match on (e.g. plant name, street number, street name, city, state)

2. Keep only the unique combination of these variables in each of the respective datasets

3. Perform a one-to-one merge across these characteristics

4. Save matched results

5. Loop back to beginning, removing matched results

This basic loop is performed for over 100 unique combinations of plant level characteristics for each SSEL year in the data, but a plant can only match once within the SSEL year loop. This creates a maximum of 20 possible matches for each plant. For various reasons some plants cannot be matched at all. Table A.2 details the various match statistics for the initial match to the SSEL (Column 2) and then after linking the SSEL to the LBD (Column 3). These statistics only correspond to the "1990 states" used to construct the cohorts (i.e. IL, MD, WA, WI). I then select the modal LBD match across all possible matches to construct the link. In the event that the mode is not unique, I randomize to select the match. Column (5) details the percentage of matches that contained a non-unique mode, and thus were randomly assigned to a modal match candidate.

Table A.2: AFS to Business Register Match Statistics: Multi Year Matching Algorithm

\begin{tabular}{|c|c|c|c|c|c|}
\hline & $\begin{array}{c}\text { (1) } \\
\text { Total AFS } \\
\text { Establishments }\end{array}$ & $\begin{array}{l}\quad(2) \\
\text { SSL Match } \\
\text { Percentage }\end{array}$ & $\begin{array}{c}(3) \\
\text { LBD Match } \\
\text { Percentage }\end{array}$ & $\begin{array}{c}(4) \\
\text { Percent } \\
\text { Non-Unique LBD }\end{array}$ & $\begin{array}{l}(5) \\
\text { Percent Non-Unique } \\
\text { Mode LBD }\end{array}$ \\
\hline Match Statistics & 8777 & 0.80 & 0.78 & 0.41 & 0.03 \\
\hline
\end{tabular}




\section{B Appendix: Figures and Tables}

Figure B.1: Number of Newly Designated Nonattainment Counties: By Year

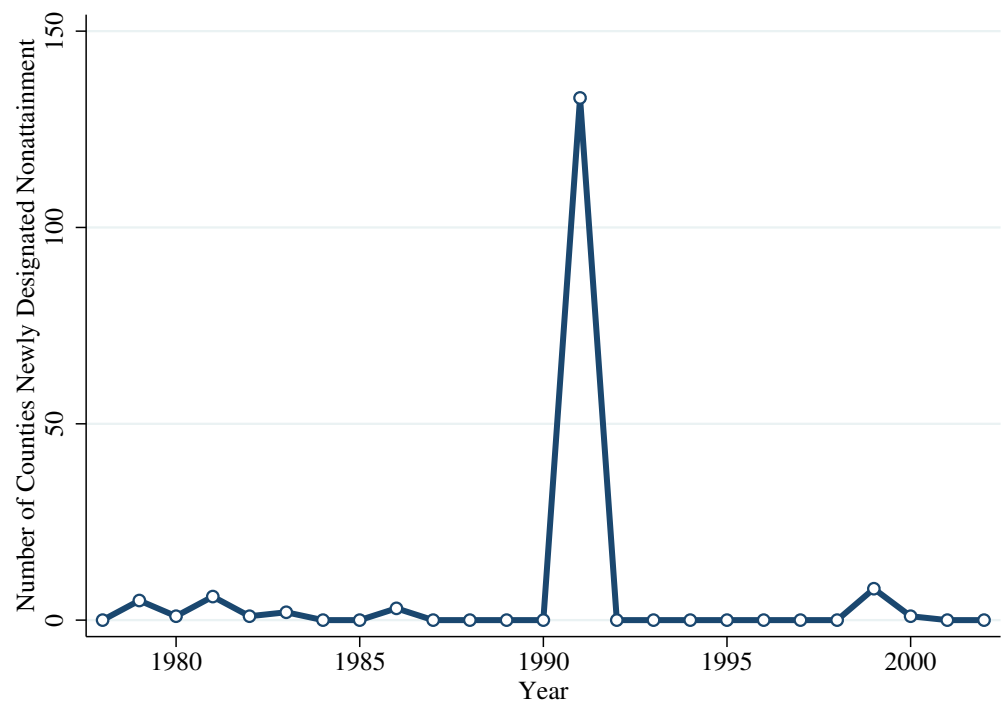

NotE: This figure shows the number of newly designated nonattainment counties by year for any pollutant regulated under the Clean Air Act. Source: EPA Greenbook.

Figure B.2: Sector Level Earnings Differences Before and After Regulation

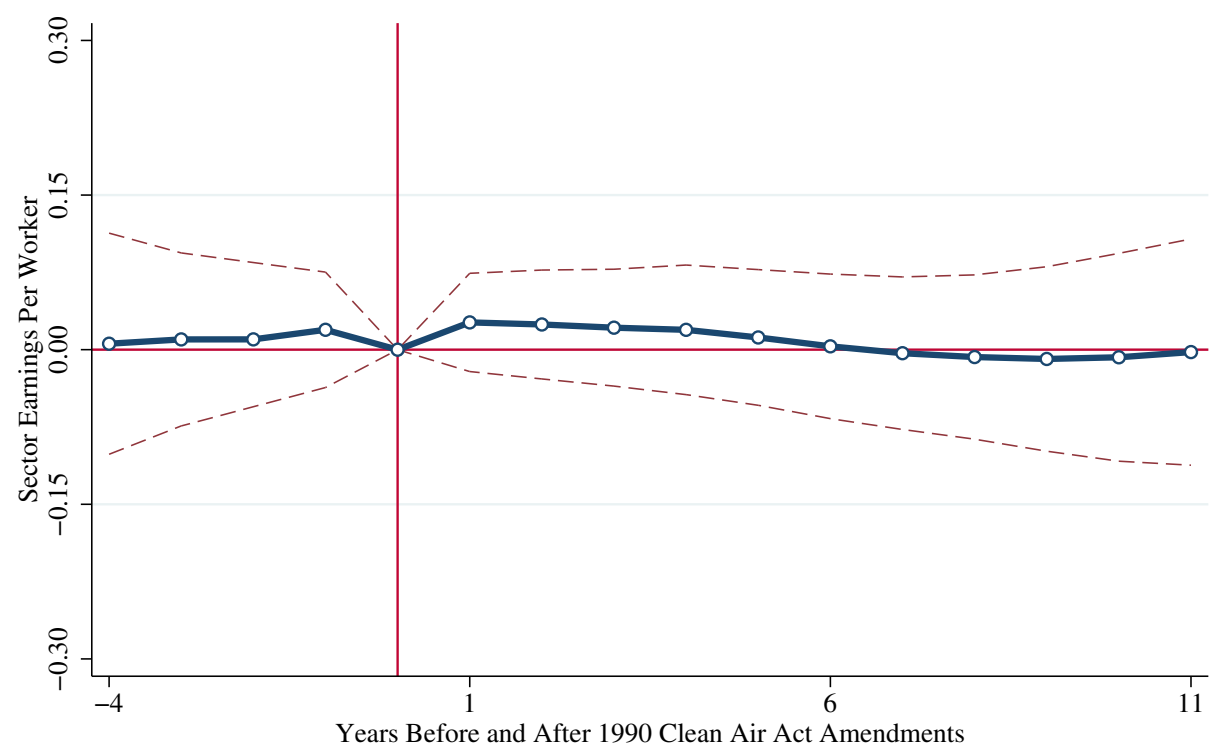

Note: Plotted are the coefficient estimates from a version of equation (5). Specifically, the figure plots the event time indicators for earnings per worker in the polluting sector of counties that switched into EPA's nonattainment designation in 1991 . The dashed lines represent $95 \%$ confidence intervals. See text for details. Source: LBD. 
Figure B.3: Cohort Wage Trends After Nonattainment Designation: "Near-Threshold Counties"

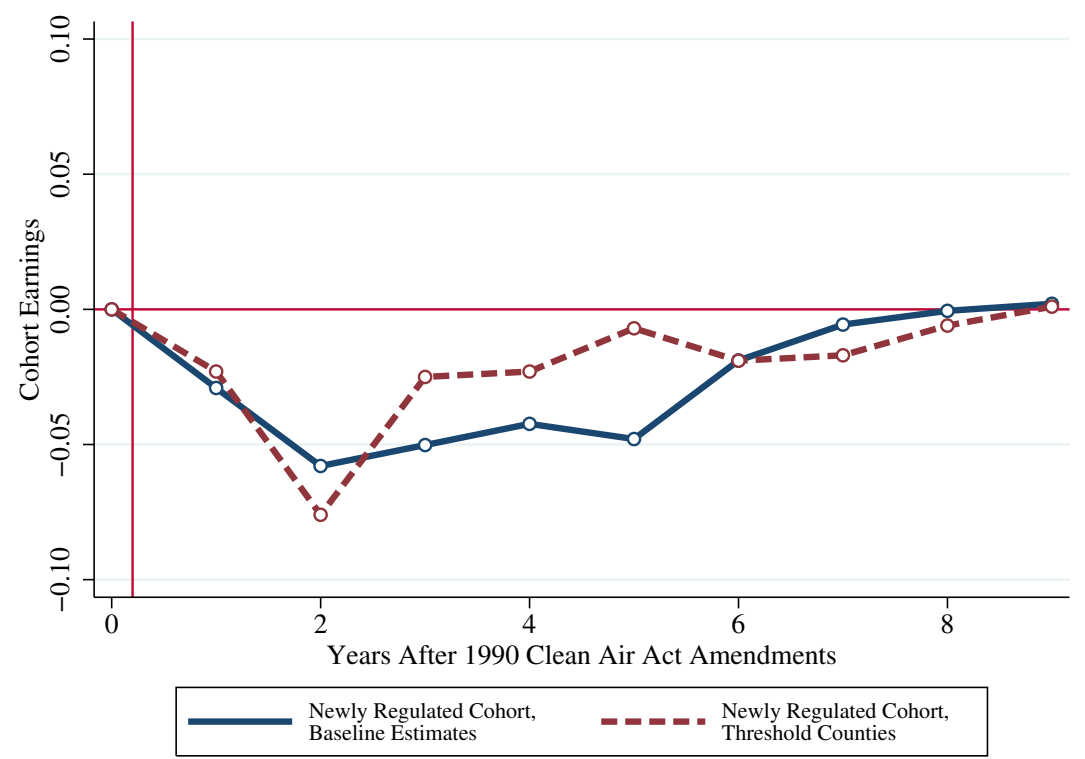

NotE: Plotted are the coefficient estimates from a version of equation (6). Specifically, each line plots the "triple-difference" regression coefficients in equation (6) for different samples. The solid line consists of the baseline earnings estimates estimated using all cohorts. The dashed line represents the earnings estimates for those cohorts in counties $+/-1$ standard deviation from the EPA's ambient air pollution, nonattainment threshold. See text for details. Source: LEHD. 
Table B.1: 1990 Decennial Census Characteristics of In-Sample and Non-Sample Counties

\begin{tabular}{|c|c|c|c|c|c|c|c|}
\hline & \multicolumn{2}{|c|}{ Attainment } & \multicolumn{2}{|c|}{ Nonattainment } & \multicolumn{2}{|c|}{ Switch Into Nonattainment } & \multirow{2}{*}{$\begin{array}{c}\text { t-statistic } \\
\text { Col. } 5 \text { - Col. } 6 \\
(7)\end{array}$} \\
\hline & $\begin{array}{c}\text { In Sample } \\
(1)\end{array}$ & $\begin{array}{l}\text { Out of Sample } \\
(2)\end{array}$ & $\begin{array}{c}\text { In Sample } \\
(3)\end{array}$ & $\begin{array}{c}\text { Out of Sample } \\
\text { (4) }\end{array}$ & $\begin{array}{c}\text { In Sample } \\
(5)\end{array}$ & $\begin{array}{c}\text { Out of Sample } \\
\text { (6) }\end{array}$ & \\
\hline Population & 70387.2 & 33998.6 & 515753.4 & 348729.8 & 87927.7 & 108540.5 & -0.90 \\
\hline Population urban (percent) & 0.529 & 0.307 & 0.791 & 0.671 & 0.470 & 0.517 & -0.81 \\
\hline Median household income (dollars) & 26549.8 & 22384.7 & 35505.1 & 31891.2 & 34893.9 & 28325.2 & 3.61 \\
\hline \multirow[t]{2}{*}{ Median home value (dollars) } & 52431.7 & 46115.8 & 90309.4 & 97000.8 & 84652.6 & 73951.7 & 1.36 \\
\hline & \multicolumn{6}{|c|}{ Panel B: County Industrial Composition } & \\
\hline Agriculture, forestry, and fisheries & 0.0237 & 0.0419 & 0.0113 & 0.0120 & 0.0247 & 0.0163 & 2.09 \\
\hline Mining & 0.00350 & 0.00766 & 0.000826 & 0.00335 & 0.00117 & 0.00550 & -4.30 \\
\hline Construction & 0.0258 & 0.0290 & 0.0303 & 0.0308 & 0.0425 & 0.0335 & 2.52 \\
\hline Manufacturing, nondurable goods & 0.0335 & 0.0355 & 0.0333 & 0.0336 & 0.0325 & 0.0323 & 0.05 \\
\hline Communications and other public utilities & 0.0112 & 0.0104 & 0.0124 & 0.0127 & 0.0148 & 0.0131 & 0.86 \\
\hline Wholesale trade & 0.0165 & 0.0141 & 0.0228 & 0.0199 & 0.0188 & 0.0172 & 1.16 \\
\hline Retail trade & 0.0802 & 0.0671 & 0.0818 & 0.0793 & 0.0809 & 0.0802 & 0.29 \\
\hline Finance, insurance, and real estate & 0.0223 & 0.0169 & 0.0348 & 0.0303 & 0.0260 & 0.0251 & 0.44 \\
\hline Business and repair services & 0.0153 & 0.0132 & 0.0233 & 0.0214 & 0.0183 & 0.0185 & 0.14 \\
\hline
\end{tabular}

Note: This table compares the various county characteristics for those counties in the LEHD base year files (MD, IL, WA, WI) to the rest of the counties in the United States, further split along the dimensions of variation in the dataset (i.e. Attainment, Nonattainment, and Switch into Nonattainment). Panel A displays basic demographic characteristics of the respective counties, whereas Panel B displays the industrial composition (as measured by employment). Industrial composition is measured as total number of workers in a given industry as a fraction of the total population. Source: 1990 Decennial Census. 
Table B.2: Effect of Sector Level Regulation on Earnings: Alternative Earnings Measures

\begin{tabular}{|c|c|c|c|c|}
\hline & \multicolumn{2}{|c|}{ Pre-Earnings } & \multicolumn{2}{|c|}{ Positive Earnings } \\
\hline & $\begin{array}{l}\operatorname{Logs} \\
(1)\end{array}$ & $\begin{array}{l}\text { Levels } \\
(2)\end{array}$ & $\begin{array}{c}\operatorname{Logs} \\
(3)\end{array}$ & $\begin{array}{l}\text { Levels } \\
(4)\end{array}$ \\
\hline Regulation $(\mathrm{t}+0)$ & $\begin{array}{l}-0.016 \\
(0.023)\end{array}$ & $\begin{array}{c}-86.285 \\
(794.579)\end{array}$ & $\begin{array}{l}-0.016 \\
(0.022)\end{array}$ & $\begin{array}{c}-1105.436 \\
(818.608)\end{array}$ \\
\hline Regulation $(\mathrm{t}+1)$ & $\begin{array}{c}-0.047 \\
(0.030)\end{array}$ & $\begin{array}{c}-956.154 \\
(1093.909)\end{array}$ & $\begin{array}{c}-0.051 \\
(0.032)\end{array}$ & $\begin{array}{c}-2092.967^{*} \\
(1194.311)\end{array}$ \\
\hline Regulation $(t+2)$ & $\begin{array}{c}-0.043^{* *} \\
(0.021)\end{array}$ & $\begin{array}{c}-1142.984 \\
(718.664)\end{array}$ & $\begin{array}{c}-0.043^{* *} \\
(0.020)\end{array}$ & $\begin{array}{c}-2154.688^{* *} \\
(855.849)\end{array}$ \\
\hline Regulation $(\mathrm{t}+3)$ & $\begin{array}{c}-0.038^{* * *} \\
(0.014)\end{array}$ & $\begin{array}{c}-1136.972^{* *} \\
(494.243)\end{array}$ & $\begin{array}{c}-0.034^{* * *} \\
(0.012)\end{array}$ & $\begin{array}{c}-1864.084^{* * *} \\
(627.626)\end{array}$ \\
\hline Regulation $(\mathrm{t}+4)$ & $\begin{array}{c}-0.045^{* * *} \\
(0.017)\end{array}$ & $\begin{array}{c}-1434.609^{* *} \\
(682.979)\end{array}$ & $\begin{array}{c}-0.035^{* *} \\
(0.017)\end{array}$ & $\begin{array}{c}-1937.368^{* *} \\
(823.276)\end{array}$ \\
\hline Regulation $(\mathrm{t}+5)$ & $\begin{array}{l}-0.019 \\
(0.019)\end{array}$ & $\begin{array}{l}-481.101 \\
(557.336)\end{array}$ & $\begin{array}{l}-0.005 \\
(0.020)\end{array}$ & $\begin{array}{l}-565.965 \\
(771.149)\end{array}$ \\
\hline Regulation $(\mathrm{t}+6)$ & $\begin{array}{l}-0.007 \\
(0.018)\end{array}$ & $\begin{array}{c}-42.994 \\
(589.769)\end{array}$ & $\begin{array}{c}0.006 \\
(0.016)\end{array}$ & $\begin{array}{c}-55.994 \\
(658.904)\end{array}$ \\
\hline Regulation $(\mathrm{t}+7)$ & $\begin{array}{l}-0.004 \\
(0.013)\end{array}$ & $\begin{array}{c}75.777 \\
(453.429)\end{array}$ & $\begin{array}{c}0.000 \\
(0.013)\end{array}$ & $\begin{array}{l}-163.088 \\
(543.281)\end{array}$ \\
\hline Regulation $(t+8)$ & $\begin{array}{c}0.001 \\
(0.009)\end{array}$ & $\begin{array}{c}271.191 \\
(334.411)\end{array}$ & $\begin{array}{c}0.009 \\
(0.012)\end{array}$ & $\begin{array}{c}377.890 \\
(440.596)\end{array}$ \\
\hline 9 Year Total & $\begin{array}{c}-0.196^{*} \\
(0.106)\end{array}$ & $\begin{array}{c}-4473.159 \\
(3369.741)\end{array}$ & $\begin{array}{l}-0.158 \\
(0.097)\end{array}$ & $\begin{array}{c}-8780.517^{\text {** }} \\
(3937.052)\end{array}$ \\
\hline $\mathrm{N}$ & 6847 & 6847 & 6748 & 6748 \\
\hline Cohort FE & $\mathrm{X}$ & $\mathrm{X}$ & $\mathrm{X}$ & $\mathrm{X}$ \\
\hline Experience & $\mathrm{X}$ & $\mathrm{X}$ & $\mathrm{X}$ & $\mathrm{X}$ \\
\hline County Trends & $\mathrm{X}$ & $\mathrm{X}$ & $\mathrm{X}$ & $\mathrm{X}$ \\
\hline
\end{tabular}

Note: This table reports regression coefficients from equation (6). Each column corresponds to a different regression, where the results are presented for two different samples as indicated in the table headings. The "Pre-Earnings" sample replaces missing earnings observations with the last observed earnings record of a particular worker. The "Positive Earnings" model restricts the sample to include only those workers who report non-missing earnings in every year of the sample. An observation is a cohort $\times$ year so that each cohort county has two observations per year. Standard errors are in parentheses and are clustered within each county. The baseline sample is estimated using three different log specifications (columns (1) and (3)), and exponentiated coefficients are reported using the translation $\left(\exp \left(\eta_{1}^{k}\right)-1\right)$. The regressions are weighted by the 1990 cohort size. The final row of the table reports the discounted sum of the coefficients using a 4 percent annual discount rate (with discount factor $\beta$ ). Columns (1) and (3) use the translation $\sum_{k=0}^{8} \beta^{k}\left(\exp \left(\eta_{1}^{k}\right)-1\right)$. Standard errors for the final row are calculated using the delta method. Earnings are reported in $1990(\$)$. See text for details. Source: LEHD. ${ }^{* * *},{ }^{* *},{ }^{*}$ denotes statistical significance at the 1, 5, and 10 percent levels, respectively. 
Table B.3: Effect of Sector Level Regulation on Non-Employment

\begin{tabular}{lccc}
\hline & & & \\
& $(1)$ & $(2)$ & $(3)$ \\
\cline { 2 - 4 } Regulation $(\mathrm{t}+0)$ & 0.026 & 0.010 & 0.024 \\
& $(0.070)$ & $(0.051)$ & $(0.046)$ \\
Regulation $(\mathrm{t}+1)$ & 0.032 & 0.019 & 0.030 \\
& $(0.054)$ & $(0.039)$ & $(0.037)$ \\
Regulation $(\mathrm{t}+2)$ & $0.060^{*}$ & 0.050 & 0.059 \\
& $(0.034)$ & $(0.039)$ & $(0.046)$ \\
Regulation $(\mathrm{t}+3)$ & $0.056^{*}$ & 0.050 & 0.056 \\
& $(0.033)$ & $(0.040)$ & $(0.045)$ \\
Regulation $(\mathrm{t}+4)$ & $0.086^{*}$ & 0.082 & 0.086 \\
& $(0.046)$ & $(0.050)$ & $(0.054)$ \\
Regulation $(\mathrm{t}+5)$ & 0.035 & 0.034 & 0.035 \\
& $(0.031)$ & $(0.032)$ & $(0.034)$ \\
Regulation $(\mathrm{t}+6)$ & 0.023 & 0.024 & 0.023 \\
& $(0.033)$ & $(0.031)$ & $(0.031)$ \\
Regulation $(\mathrm{t}+7)$ & 0.027 & 0.032 & 0.028 \\
& $(0.028)$ & $(0.024)$ & $(0.022)$ \\
Regulation $(\mathrm{t}+8)$ & 0.022 & 0.030 & 0.023 \\
& $(0.037)$ & $(0.030)$ & $(0.027)$ \\
\cline { 2 - 4 } 9 Year Total & $0.367^{* *}$ & $0.330^{*}$ & $0.364^{*}$ \\
& $(0.174)$ & $(0.190)$ & $(0.217)$ \\
$\mathrm{N}$ & 6847 & 6847 & 6847 \\
\hline Cohort FE & $\mathrm{X}$ & $\mathrm{X}$ & $\mathrm{X}$ \\
Experience & & $\mathrm{X}$ & $\mathrm{X}$ \\
County Trends & & & $\mathrm{X}$ \\
\hline
\end{tabular}

Note: This table reports regression coefficients from equation (6). Each column corresponds to a different regression, where the dependent variable is the average quarters of non-employment in a given year $\in[0,4]$. An observation is a cohort $\times$ year so that each cohort county has two observations per year. Standard errors are in parentheses and are calculated allowing for an arbitrary variancecovariance matrix within each county. The sample is estimated using three different specifications (columns (1)-(3)). The regressions are weighted by the 1990 cohort size. The final row of the table reports the sum of the coefficients. Standard errors for the final row are calculated using the delta method. See text for details. Source: LEHD. ${ }^{* * *}, * * *$ denotes statistical significance at the 1,5 , and 10 percent levels, respectively. 